\title{
Effect of the end cross beams on the railway induced vibrations of short girder bridges
}

\author{
E.Moliner ${ }^{\mathrm{a}, *}$, A.Romero ${ }^{\mathrm{b}}$, P.Galvín ${ }^{\mathrm{b}}$, M.D.Martínez-Rodrigo ${ }^{\mathrm{a}}$ \\ ${ }^{a}$ Universitat Jaume I, Department of Mechanical Engineering and Construction, 12071 Castellón, \\ Spain \\ ${ }^{b}$ Escuela Técnica Superior de Ingeniería, Universidad de Sevilla, Camino de los Descubrimientos s/n, \\ 41092 Sevilla, Spain
}

\begin{abstract}
This work is devoted to the analysis of the railway-induced vertical vibrations of simplysupported double track bridges composed by pre-stressed concrete girder decks. Despite the low torsional stiffness that this particular deck configuration exhibits, several structures of this type do exist in both conventional and high-speed railway lines in Spain. Even though railway administrators recommend the construction of transverse or end beams bracing the longitudinal girders at the supports in girder bridges, in several occasions these elements are not built in order to accelerate the construction process. The aim of this study is to evaluate the beneficial effect of installing these transverse beams on the vertical dynamic response of the aforementioned structures and to determine what particular bridges are most affected by the presence of these elements. To this end, a representative ensemble of girder bridges covering a range of span lengths $L$ between 10 $\mathrm{m}$ and $25 \mathrm{~m}$ has been predimensioned and their dynamic behaviour has been predicted by a finite element model that adopts common assumptions in engineering practice. Conclusions show that installing these elements is particularly relevant in the case of short (10-12.5 m) oblique bridges with a low number of longitudinal girders for a particular deck bending stiffness, leading to an important increase of the first torsion and first transverse bending natural frequencies and to a reduction of the structural response. Finally, experimental measurements on a real bridge belonging to the Madrid-Sevilla high-speed line are included in the final section to illustrate the theoretical derivations.
\end{abstract}

Keywords: Railway bridges, bracing beams, bridge dynamics, vertical acceleration, finite elements

\section{Introduction}

Regarding the design or upgrading of simply-supported (SS) railway bridges of shortto-medium span lengths, an issue of concern in high-speed lines is the vertical acceleration levels at the platform. One remarkable example of its relevance was documented in

\footnotetext{
*Corresponding author. Tel.:+34964387468; fax:+34964728106

Email address: molinere@uji.es (E.Moliner)
} 
5 [1], where excessive transverse vibration levels were reported in structures belonging to the first European high-speed line, Paris-Lyon. Shortly after the opening, a few SS bridges of moderate spans (ranging from 14 to $20 \mathrm{~m}$ ) suffered from ballast destabilization despite they were designed following the reference regulations at that time (UIC 7761R, [2]). Subsequent dynamic analyses and experimental tests performed by the European

10 Rail Research Institute (ERRI) demonstrated that the vertical accelerations caused by resonance effects were responsible for this adverse consequence.

From that time to the present the deck vertical acceleration is one of the most demanding specifications for the design or assessment of short SS railway bridges [3], which constitutes one of the Serviceability Limit States for traffic safety prescribed by Eurocode

15 (EC) [4] and is limited to $3.5 \mathrm{~m} / \mathrm{s}^{2}$ for ballasted tracks. In this context the development of sufficiently accurate numerical models capable of predicting the dynamic performance of the structure becomes crucial for engineers in practical applications.

A number of research works presented in recent years give a further insight on the accuracy of the approaches commonly used for the estimation of the dynamic response

20 of railway bridges under train excitation. A better understanding of the key parameters affecting the numerical predictions is of great interest in bridge engineering, enabling to avoid superfluous refinements in the numerical models, which unnecessarily increase computational costs, and also to improve the design codes. In [5] Moliner et al. addressed the importance of using three dimensional (3D) plate numerical models and the

25 effects of including the flexibility of the elastic supports for the evaluation of the vertical acceleration levels. Liu et al.[6], Arvidsson et al. [7] and Doménech et al.[8] investigated the conditions under which train-bridge interaction should be considered for the dynamic analysis. Cantero et al. [9] investigated the underestimation of the load effects in simply supported railway bridges under the passage of trains as a result of considering that the

30 maximum response takes place at mid-span, which is a frequent assumption in bridge engineering. Additional studies have also shown that the maximum vertical accelerations do not necessarily occur at mid-span [10, 11].

However, as stated in previous works [12, 13], the dynamic response of short-tomedium span SS railway bridges is difficult to predict during the design or upgrading 35 stages, since it can be significantly affected by the dynamic characteristics of the track and the vehicle that are not well known. Additionally, in double track bridges of short spans, due to their span to width ratios close to unity, the contribution of modes different from longitudinal bending ones, such as the first torsion and transverse bending modes with usually close natural frequencies may affect significantly the maximum response

40 of the bridge [5]. In this regard experimentally testing the structures becomes crucial to correctly understand the influence of uncertain parameters and to update realistic numerical models.

The number of reported experimental campaigns performed on short-to-medium span SS railway bridges is still scarce unless a particular behaviour of the bridge is expected,

45 as is the case of portal frames or soil-steel composite railway bridges [14, 15], where the soil-structure interaction effects (SSI) can play an important role. Xia et al. 16] performed a simple experimental campaign on a railway bridge of several SS spans of $24 \mathrm{~m}$ length, focusing on the validation of a proposed computational dynamic model for train-bridge interaction. Rebelo et al. [13] carried out in situ tests on several single

50 span ballasted railway bridges, showing the existence of important non-linear effects associated to the variations of the identified natural frequencies with the amplitude of 
vibration. Velarde et al. [17] studied the dynamic response of a SS, I-girder railway bridge with a skewed deck. The modal parameters of the structure were first obtained from experimental tests and a 3D finite element (FE) model was calibrated to simulate 55 the bridge response under railway excitation, showing a reasonably good correspondence with the measured deck accelerations under the passage of a real train. However, due to the high computational cost of the simulations, a simplified two-dimensional (2D) model was used to compute the envelope of maximum displacements and accelerations for each velocity under the circulation of a great number of train compositions, as required by the European Standards.

In a previous work the authors of the present manuscript performed an experimental campaign on a short, double track SS bridge belonging to a high-speed railway line in Spain [18], with a deck composed of five longitudinal pre-stressed concrete girders. The bridge was selected due to its prominent obliquity and its dimensions, with a span

65 length similar to the deck width. Both features along with the eccentricity of the train loads, make this structure susceptible to experience a dynamic response with a high participation of modes different from the longitudinal bending one. Additionally, in a preliminary numerical evaluation of the bridge [19] an important transverse vibration response was predicted at the platform. In this work, several FE models which adopt 70 common assumptions in engineering practice and in accordance with the European Standards [4, 20] were updated with the experimental measurements, showing a reasonably good correspondence in terms of frequencies and mode shapes, and also in terms of the deck vertical acceleration response under the passage of high-speed trains. However, the calibration of the first torsion mode and other modes with transverse deformation was

75 less accurate. In the authors opinion one of the reasons of this miss prediction of the transverse behaviour could be associated to the presence of transverse beams bracing the longitudinal girders of the deck at the supports position, which were not included in the numerical models.

Transverse bracing beams (Fig,2) are generally reinforced concrete, cast-in-place gird-

so ers that are often present along the deck edges at the supports of some SS girder bridges of short spans. They facilitate the increase of the spacing between the longitudinal girders without any thickening of the upper concrete slab. However, their presence leads to higher construction costs and, for that reason, occasionally these elements are missing or do not reach the lower face of the slab, lowering their beneficial stiffening effect at the

${ }_{85}$ border. In any case, the influence of these elements on the dynamic response of the deck is not well known. Earlier studies have pointed out the importance of considering the transverse deformations in the free vibration behaviour of certain types of bridges, such as multi-girder, single-cell and multi-cell box bridges during the design stage 21]. Huang and Wang analysed the transverse bending of highway multigirder bridges under the

90 passage of multiple vehicles [22] using the grillage method, Rattigan et al. 23] simulated dynamic loads on multigirder bridges using a 3D FE model of the bridge, which was apparently more realistic than the grillage beam model implemented in previous works. Finally Deng and Cai 24] proposed simple expressions for calculating the impact factors applicable to new and existing multigirder highway bridges. In the cited literature,

95 mainly devoted to highway bridges, the attention is focused on the development of new approximate models for the analysis of multigirder highway bridges during the design stage, and on the main parameters of the bridge affecting the impact factors associated to stresses and deflections. However, the effect of the transverse bracing beams on the 
modal parameters of the bridge and on the acceleration levels, which is a main concern in short SS railway bridges, deserves further clarification.

The objective of this work is to evaluate the effect of the transverse bracing beams on the dynamic response of SS girder bridges of short-to-medium span lengths and the correlation with other geometric and mechanical properties such as the deck flexural stiffness, its obliquity and the vertical flexibility of the elastomeric bearings at the supports. The

105 main results of the study are validated with the experimental campaign performed on an existing SS girder bridge that was documented in [18]. The conclusions presented herein provide an enhanced understanding of the dynamic response of these short structures and may contribute to the development and validation of safe and accurate numerical models useful for practical applications.
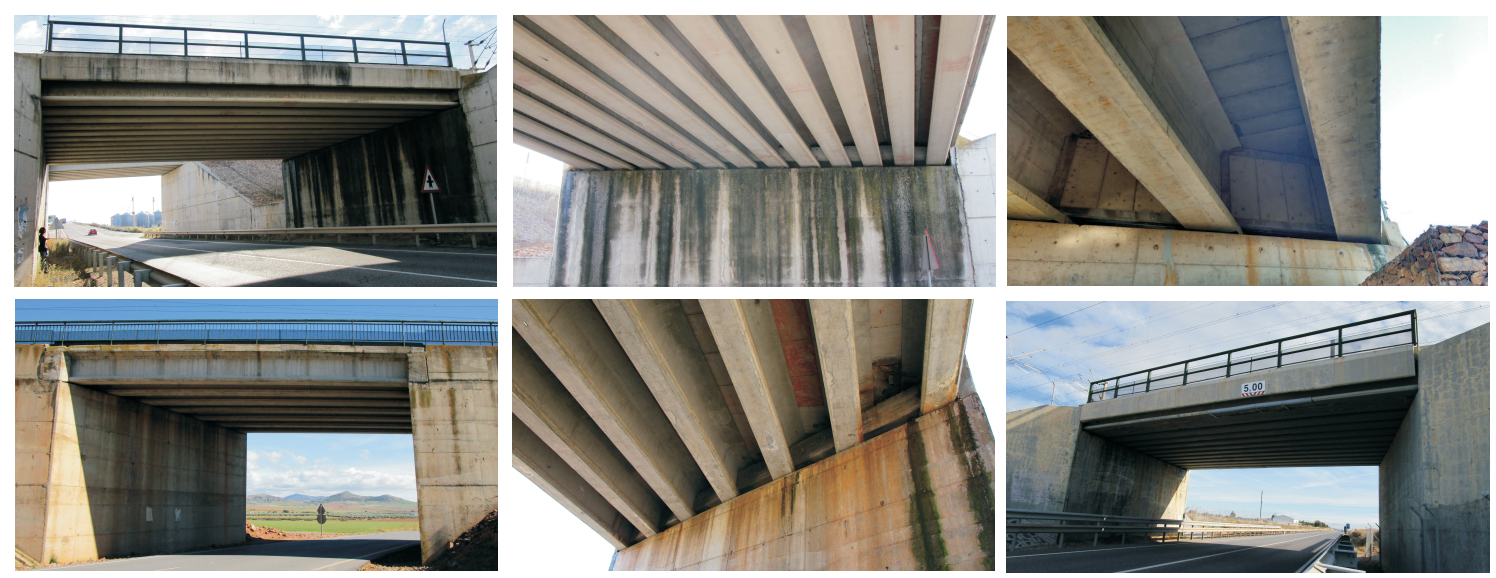

Figure 1: SS girder bridges of the high-speed railway line Madrid-Seville.

\section{Representative ensemble of SS girder bridges for railway lines}

As indicated in [5] pre-stressed concrete girder bridges are becoming less popular in high-speed lines of new construction due to their lower torsional resistance when compared to other deck geometries. However they are usual in conventional lines and, with the advent of modern railway transportation systems, these bridges are often conditioned to higher design speeds. Also the first high-speed railway line in Spain, Madrid-Seville, which was opened in 1992, was built with an important number of prestressed concrete girder bridges.

This type of deck is composed by a reinforced concrete, cast-in-place upper slab resting over a series of precast prestressed longitudinal girders. The girders lean on the

${ }_{120}$ supports through laminated rubber bearings. In many of these structures the ends of the longitudinal girders at the supports are braced by a concrete, cast-in-place transverse beam of rectangular cross section. These bridges usually cover spans between $10 \mathrm{~m}$ and $25 \mathrm{~m}$, with slenderness ratios no higher than 1/13. Fig 1 shows several girder bridges of the spanish high-speed railway line Madrid-Seville.

125 In order to numerically evaluate the effect of the transverse bracing beams on the bridge dynamic behaviour and also the correlation with the span length, deck obliquity 
and flexibility of the elastomeric bearings, a representative ensemble of double track, SS girder bridges, covering the range of span lengths between $10 \mathrm{~m}$ and $25 \mathrm{~m}$ has been designed for this study. Figure 2 shows a general cross section of the decks, where the main dimensions of the elements $h, d_{g}, h_{g}, h_{t}$ and additional mechanical properties are provided in Table 1

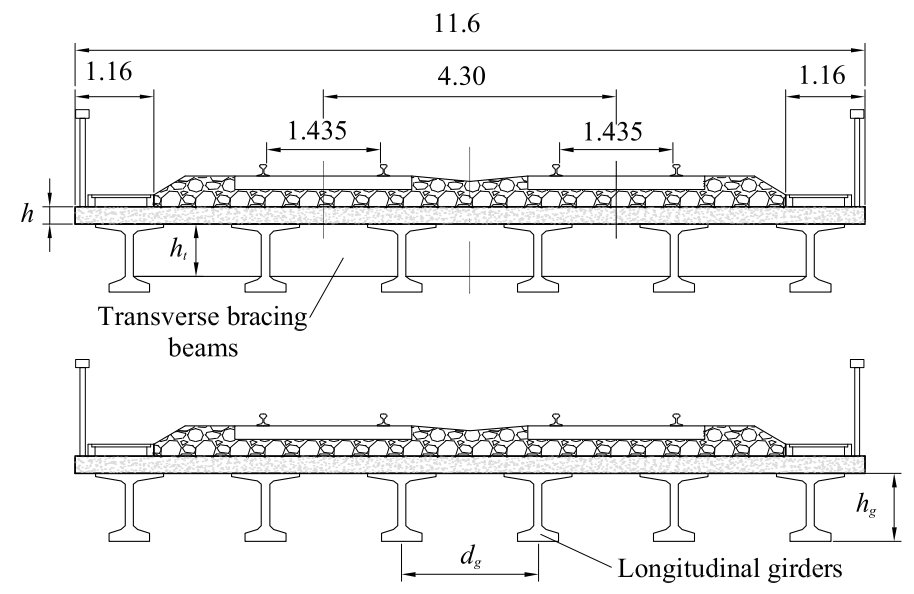

Figure 2: Cross section of the girder bridges of study. Top: cross section at the abutment; bottom: intermediate cross section.

For each span length a different number of longitudinal girders $\left(N_{g}=5\right.$ or $\left.N_{g}=6\right)$ is considered. Also, two flexural stiffness ratios $L / \delta$ (span length/maximum vertical displacement under static UIC-71 train loading 20]) are studied: in the range [20003000], representative of conventional lines bridges; and $L / \delta>3000$, common values for high-speed lines structures. The flexibility of the laminated rubber bearings is given in Table 1 in terms of the vertical stiffness of each elastic support, $k_{v, d y n}$. In this regard, two different cases are considered for eack deck: (i) the simply-supported case (SS), neglecting the flexibility of these elements $\left(k_{v, d y n}=\right.$ rigid); and (ii) the elastically supported case (ES), considering a nominal value for their vertical stiffness. Finally, two different levels of deck skewness are considered, $0^{\circ}$ and $45^{\circ}$. The nominal value for the concrete strength $f_{c k}$ assumed for the cast-in-place elements, i.e. the upper slab and the transverse bracing beams, is $30 \mathrm{MPa}$; for the longitudinal girders a value of $f_{c k}=50 \mathrm{MPa}$ is considered.

With the aforementioned combinations a total number of 108 girder bridges are predesigned, with the main purpose of constituting an envelope of the different SS girder bridges that can be found in conventional and high-speed railway lines.

\section{Numerical model}

The so-called isotropic-plate + beams finite element model developed and fully described in a previous work [18] has been used to numerically evaluate the dynamic behaviour of the girder bridges (see Fig 3 ). The main features of the model, implemented in the commercial code ANSYS, are the following: 


\begin{tabular}{|c|c|c|c|c|c|c|c|c|c|}
\hline \multirow[t]{2}{*}{ Span } & \multirow{2}{*}{$h[\mathrm{~m}]$} & \multirow{2}{*}{$h_{t}[m]$} & \multicolumn{4}{|c|}{ Longitudinal girders } & \multirow{2}{*}{$\begin{array}{c}\text { Mass } \\
{[\mathrm{kg} / \mathrm{m}]}\end{array}$} & \multirow{2}{*}{$\begin{array}{c}\text { Supports } \\
k_{v, \text { dyn }}[N / m]\end{array}$} & \multirow{2}{*}{$L / \delta$} \\
\hline & & & $N_{g}$ & $d_{g}[\mathrm{~m}]$ & $h_{g}[\mathrm{~m}]$ & $I_{h}\left[\mathrm{~m}^{4}\right]$ & & & \\
\hline \multirow{4}{*}{$L=10 \mathrm{~m}$} & 0.25 & 0.42 & 5 & 2.275 & 0.6 & 0.01098 & 19066 & rigid, $9.7 \mathrm{E} 8$ & 2049 \\
\hline & 0.22 & 0.42 & 6 & 2.0 & 0.6 & 0.01098 & 18765 & rigid, $8.34 \mathrm{E} 8$ & 2119 \\
\hline & 0.25 & 0.41 & 5 & 2.275 & 0.65 & 0.02150 & 21395 & rigid, $1.57 \mathrm{E} 9$ & 3320 \\
\hline & 0.22 & 0.41 & 6 & 2.0 & 0.65 & 0.02150 & 21560 & rigid, $1.47 \mathrm{E} 9$ & 3740 \\
\hline \multirow{3}{*}{$L=12.5 \mathrm{~m}$} & 0.25 & 0.62 & 6 & 2.0 & 0.8 & 0.02278 & 19995 & rigid, $7.56 \mathrm{E} 8$ & 2229 \\
\hline & 0.22 & 0.6 & 5 & 2.275 & 0.85 & 0.04446 & 21542 & rigid, $1.60 \mathrm{E} 9$ & 3607 \\
\hline & 0.22 & 0.61 & 6 & 2.0 & 0.85 & 0.04339 & 22100 & rigid, $1.31 \mathrm{E} 9$ & 3560 \\
\hline \multirow{4}{*}{$L=15 \mathrm{~m}$} & 0.22 & 0.92 & 5 & 2.275 & 1.1 & 0.03703 & 19485 & rigid, $8.93 \mathrm{E} 8$ & 2154 \\
\hline & 0.25 & 0.77 & 6 & 2.0 & 1.0 & 0.03961 & 20355 & rigid, $7.44 \mathrm{E} 8$ & 2154 \\
\hline & 0.25 & 0.80 & 5 & 2.275 & 1.05 & 0.08258 & 23221 & rigid, $1.54 \mathrm{E} 9$ & 3710 \\
\hline & 0.25 & 0.81 & 6 & 2.0 & 1.05 & 0.07423 & 23510 & rigid, & 3657 \\
\hline \multirow{4}{*}{$L=17.5 \mathrm{~m}$} & 0.25 & 0.91 & 5 & 2.275 & 1. & 0.09131 & 22018 & rigid, $9.89 \mathrm{E} 8$ & 2506 \\
\hline & 0.25 & 0.97 & 6 & 2.0 & 1.2 & 0.06195 & 20715 & rigid, $6.88 \mathrm{E} 8$ & 2090 \\
\hline & 0.25 & 1.01 & 5 & 2.275 & 1.25 & 0.11476 & 22745 & rigid, $1.22 \mathrm{E} 9$ & 3079 \\
\hline & 0.25 & 1.01 & 6 & 2.0 & 1.25 & 0.11476 & 24050 & rigid, $1.01 \mathrm{E} 9$ & 3495 \\
\hline \multirow{4}{*}{$L=20 \mathrm{~m}$} & 0.25 & 1.11 & 5 & 2.275 & 1.4 & 0.13457 & 22393 & rigid, $9.26 \mathrm{E} 8$ & 2441 \\
\hline & 0.25 & 1.17 & 6 & 2.0 & 1.4 & 0.09029 & 21075 & rigid, $6.42 \mathrm{E} 8$ & 2031 \\
\hline & 0.25 & 1.2 & 5 & 2.275 & 1.45 & 0.17098 & 23896 & rigid, $1.27 \mathrm{E} 9$ & 3387 \\
\hline & 0.25 & 1.16 & 6 & 2.0 & 1.45 & 0.16571 & 24590 & rigid, $1.06 \mathrm{E} 9$ & 3351 \\
\hline \multirow{4}{*}{$L=22.5 \mathrm{~m}$} & 0.25 & 1.31 & 5 & 2.275 & 1.6 & 0.18768 & 24590 & rigid, $8.72 \mathrm{E} 8$ & 2383 \\
\hline & 0.25 & 1.31 & 6 & 2.0 & 1.6 & 0.18768 & 24078 & rigid, $8.27 \mathrm{E} 8$ & 2717 \\
\hline & 0.25 & 1.4 & 5 & 2.275 & 1.65 & 0.23652 & 24396 & rigid, $1.18 \mathrm{E} 9$ & 3387 \\
\hline & 0.25 & 1.4 & 6 & 2.0 & 1.65 & 0.22778 & 25130 & rigid, $9.85 \mathrm{E} 8$ & 3223 \\
\hline \multirow{4}{*}{$L=25 \mathrm{~m}$} & 0.25 & 1.41 & 5 & 2.275 & 1.7 & 0.21812 & 22956 & rigid, $7.26 \mathrm{E} 8$ & 2037 \\
\hline & 0.25 & 1.41 & 6 & 2.0 & 1.7 & 0.21812 & 24303 & rigid, $6.89 \mathrm{E} 8$ & 2320 \\
\hline & 0.25 & 1.6 & 5 & 2.275 & 1.85 & 0.131500 & 24896 & rigid, 1.11E9 & 3126 \\
\hline & 0.25 & 1.61 & 6 & 2.0 & 1.85 & 0.16087 & 25670 & rigid, $9.23 \mathrm{E} 8$ & 3106 \\
\hline
\end{tabular}

Table 1: Main properties of the girder bridges of study

- The behaviour of the reinforced concrete slab is simulated by means of an isotropic thin plate discretised with shell elements with 6 degrees of freedom (dof) per node. The element size is chosen to adequately reproduce the wavelengths of the modes used in the analysis.

- Different mass density elements are defined in order to concentrate the weight of the ballast, sleepers and rails over the platform area.

- The longitudinal girders are included in the model as beam elements with 6 dof per node. These nodes are connected to those of the upper plate right above them by means of rigid kinematic constraints. The distance between the plate and the beams nodes equals the real separation between the slab neutral plane and the center of mass of the girders.

- The laminated rubber bearings of the bridge are introduced in discrete positions by means of longitudinal springs with vertical constant stiffness $k_{v, d y n}$. The material 


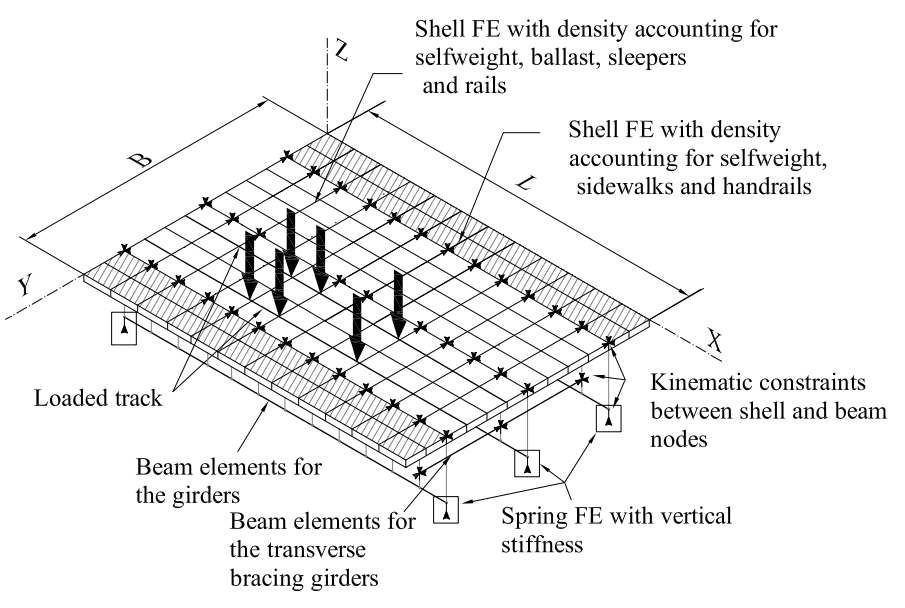

Figure 3: FE model.

damping present in these elements is not included in a first approach as its effect on the natural frequencies of the bridges will be very small, and due to the inherent uncertainty on the determination of this parameter. Instead, this effect is included in an overall modal damping parameter directly in the modal equations of motion

- A point load model is adopted for the railway excitation, therefore neglecting vehicle-structure interaction effects. Since the track is not included in the model either, when a load enters or exits the bridge a transient phenomenon takes place due to the presence of the elastic bearings, which leads to unrealistic high-frequency modal contributions of the plate. This numerical problem has been solved in the model including the distributive effect of rails, sleepers and ballast during the application process of the wheel loads when they are close to the abutments. To this end, the value of each axle load is modulated throughout a load-print distributive function based on the Zimmerman-Timoshenko solution for an infinite beam on Winkler foundation, as described in 19].

- The dynamic equations of motion are transformed into modal space and numerically integrated by the Newmark-Linear Acceleration algorithm. The time-step is defined as $1 / 25$ times the smallest period used in the analysis (mode contributions up to $30 \mathrm{~Hz}$ as per European Standards [20]). This value ensures the convergence of the solution with the time step, avoiding period elongation errors and enabling to capture properly the oscillations of the modal loading functions and the peak responses obtained by the summation of all modal contributions.

- In contrast with the model used in 18], in this work the transverse bracing beams of the deck located at the abutments position are included in the model as beam elements with 6 dof per node, as can be seen in Fig 3 Their nodes are connected to the upper slab and also to the end nodes of the longitudinal girders through kinematic constraints. 
4. Influence of the transverse bracing beams on the dynamic behaviour of girder bridges: parametric analysis

In the following subsections the effects of the transverse bracing beams on the dynamic behaviour of the ensemble of realistic bridges of study is evaluated.
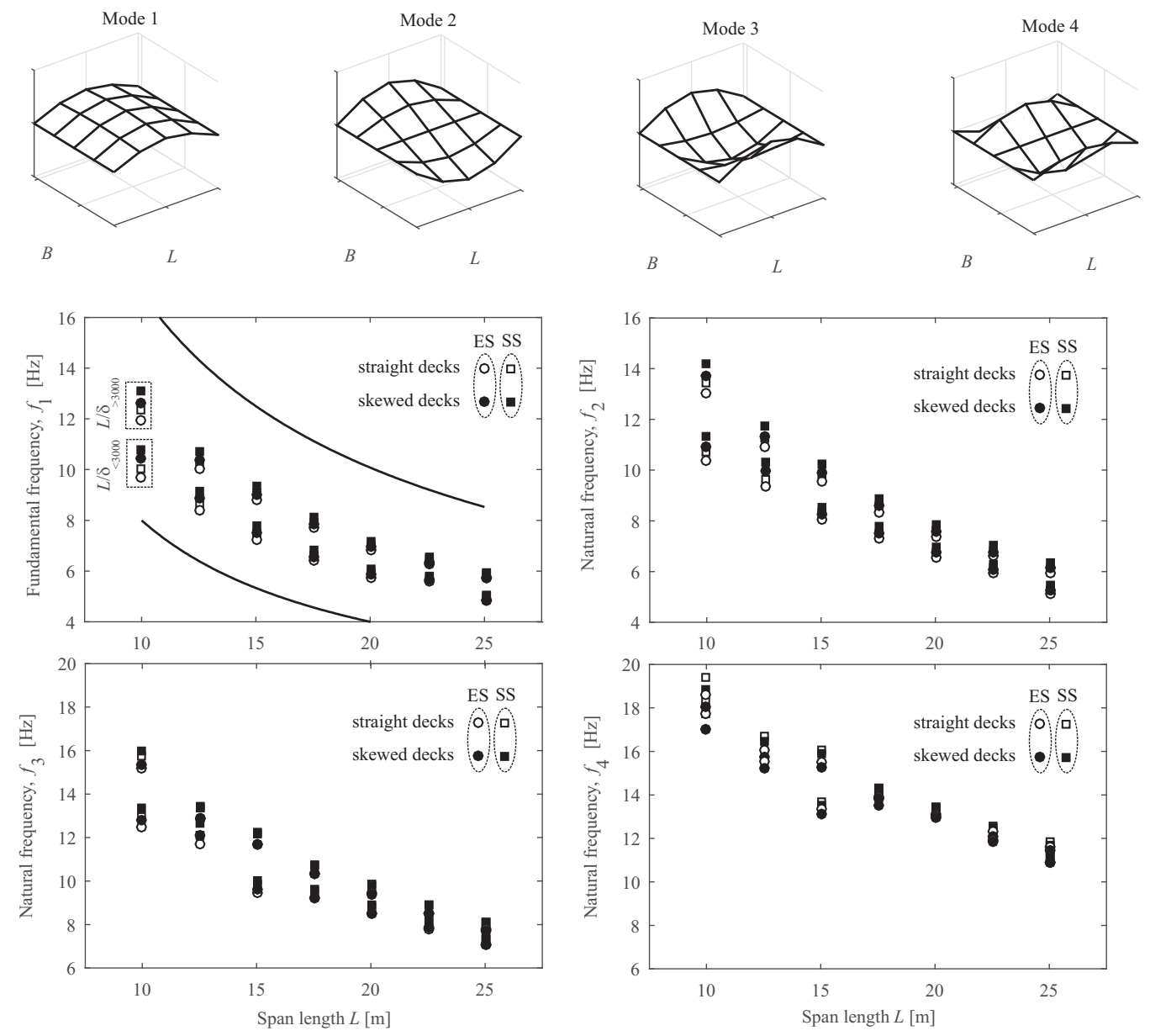

Figure 4: First four mode shapes and frequencies of the bridges of study.

First, a modal analysis is performed on the bridges defined in Section 2 using the numerical model previously described. The natural frequencies and mode shapes are predicted using two approaches: (i) including the transverse bracing beams in the FE model as seen in Fig 3 and (ii) neglecting the presence of these elements. Finally, the dynamic response of the bridges under the circulation of the ten HSLM-A trains defined in Eurocode 1 (EC1) [20] in a wide range of velocities is obtained, with the double purpose of (i) evaluating the stiffening effect of including these elements on the bridge performance, and (ii) appraising the consequences of neglecting their presence in the numerical model. 


\subsection{Natural frequencies and mode shapes}

205 4.1.1. Girder bridges without transverse bracing beams

Fig 4 shows the first four mode shapes and their natural frequencies for all the girder bridges studied in this work in the absence of the bracing beams. The fundamental frequency $f_{1}$ is always associated to the first longitudinal bending mode. For illustrative purposes, for each span length and $L / \delta$ ratio only one of the two decks $\left(N_{g}=5\right.$ or $\left.N_{g}=6\right)$

210 shown in Table 1 is chosen: (i) for $L / \delta>3000$ the decks with highest frequency values are selected; and (ii) for $L / \delta<3000$ the ones with the lowest frequencies are plotted. With this representation the frequency range considered for each span length as well as the effect of the deck parameters (obliquity, stiffness $L / \delta$ ) and supports flexibility on the natural frequencies can be seen more clearly.

Regarding the plot associated to the fundamental frequency $f_{1}$, the two solid black traces enclose the EC frequency band, which defines a range of bridge fundamental frequencies within which significant train induced vibrations are not expected in the structure at circulating speeds below $200 \mathrm{~km} / \mathrm{h}$. As can be seen, the predimensioned girder decks cover a relevant portion of the EC frequency band for each span length. The $f_{1}$ plot shows that the obliquity of the deck induces a stiffening effect on the structure, leading to an increment of the fundamental frequencies with respect to the straight case. This effect decreases with the span length. In a similar way, the presence of neoprene bearings in the calculations (ES cases) leads to a reduction of the fundamental frequency with respect to the SS cases. As stated before, the frequency variations are less significant with the increase of the span length.

The second lowest natural frequency $f_{2}$, and the subsequent ones, $f_{3}$ and $f_{4}$ are associated, respectively, to the first torsion, first transverse bending and second transverse bending modes in all the bridges of study. The evolution of $f_{2}$ under variations of the skew angle, span length and supports flexibility follows a similar pattern than the one observed for $f_{1}$, since in both mode shapes the longitudinal girders bend in a similar way. The effect of the $L / \delta$ ratios is less relevant than for the frequencies $f_{1}$ and $f_{2}$. For higher frequencies, mode shapes of torsion, longitudinal and transverse bending alternate in an unpredictable order that depends on the span length and the deck skewness. Fig 5 shows the rest of the modes up to $30 \mathrm{~Hz}$ of two particular bridges of span lengths $L=15 \mathrm{~m}$ and

\section{$235 \quad L=25 \mathrm{~m}$}

\subsubsection{Effect of the transverse bracing beams}

The influence of the transverse bracing beams on the natural frequencies of the decks is evaluated in what follows as a relative difference between the frequencies of the decks including these elements $\left(f_{i}^{\text {brace }}\right)$ and the frequencies in the absence of the transverse beams $\left(f_{i}\right)$, evaluated as Diff $f_{i}(\%)=\left(f_{i}^{b r a c e}-f_{i}\right) / f_{i} \times 100$, where $i$ is the mode number.

Fig [6 shows the relative differences for the frequencies of the first three modes of all the bridges of study considering rigid supports. The plots in the first row of the figure are associated to the bridges with straight decks, and in the second row the frequency differences associated to the skewed decks are shown. Also different markers and colours are used for the sake of clarity: the grey colour corresponds to bridges with a stiffness ratio $L / \delta$ in the range $2000-3000$, and the results in black correspond to stiffness ratios between 3000-4000. Furthermore, the square markers have been assigned to bridges with $N_{g}=6$ longitudinal girders, whereas diamonds represent bridges with $N_{g}=5$. Note that the scale of the vertical axes changes for each mode for improved visualisation. 

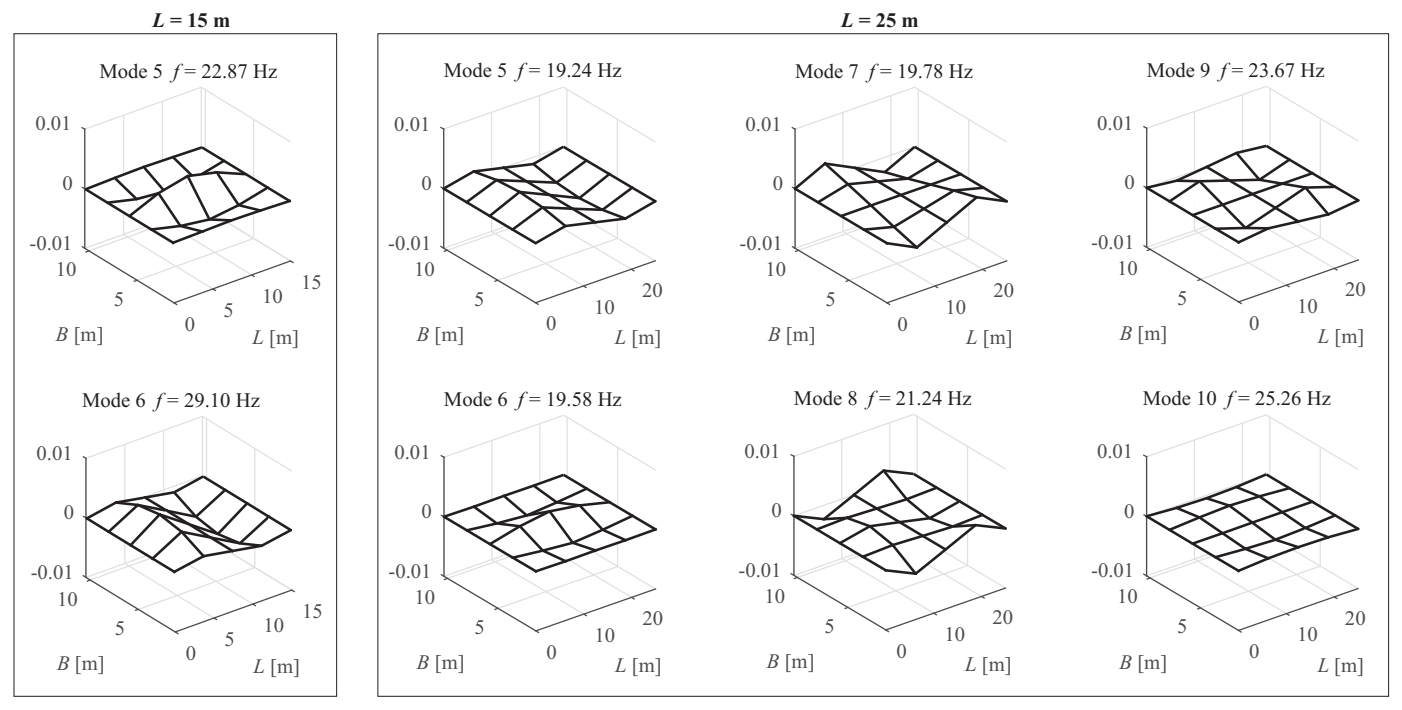

Figure 5: Modes and frequencies from 5th up to $30 \mathrm{~Hz}$. Spans $L=[1525] \mathrm{m}$
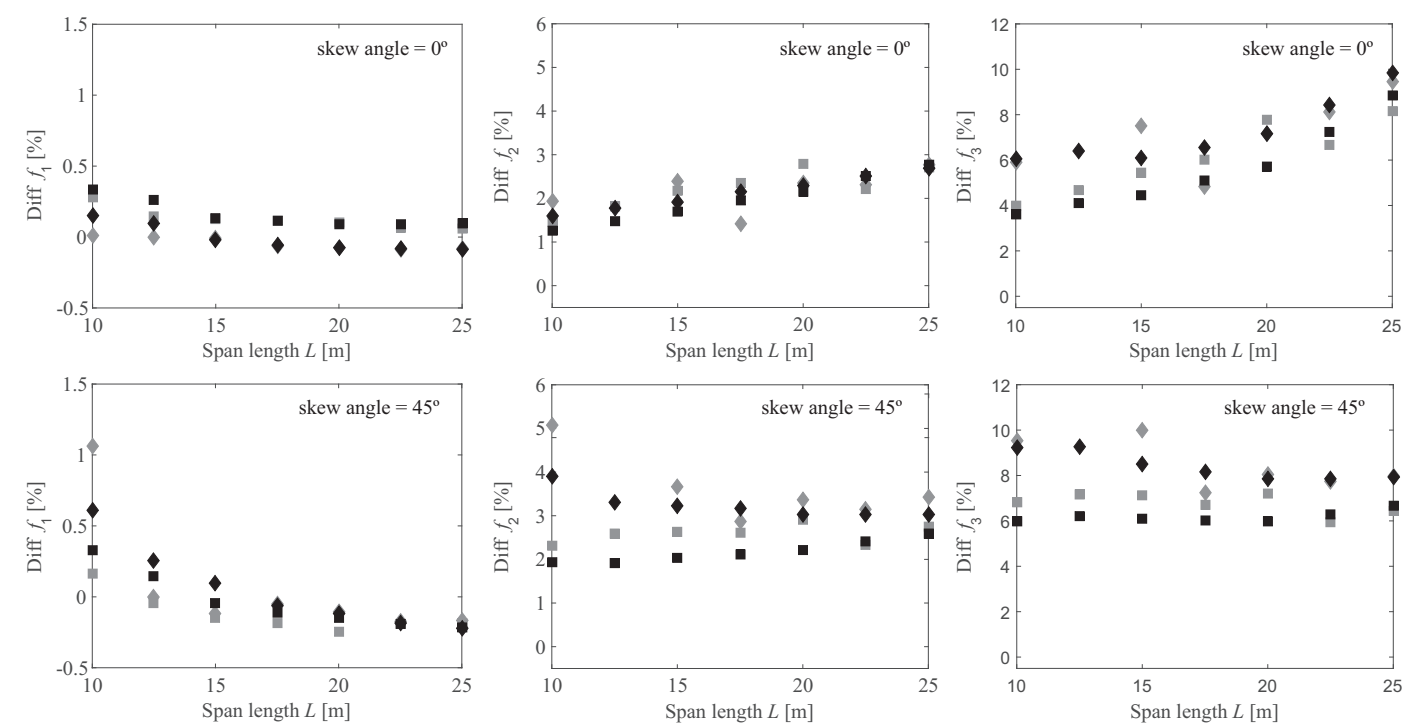

Figure 6: Differences in the prediction of the first three natural frequencies caused by the effect of the transverse bracing beams for the bridges with rigid supports $\left(k_{v, d y n}=\right.$ rigid $)$. In grey, decks with $L / \delta<3000$; in black, decks with $L / \delta>3000$. Square markers, bridges with $N_{g}=6$; diamonds for the bridges with $N_{g}=5$.

As can be seen from the plots, the presence of transverse bracing beams leads, in general, to an increment of the natural frequencies of the deck. This increment is more noticeable for the modes with significant transverse deformation, such as the first torsion mode and especially the first transverse bending mode, where the differences may attain 

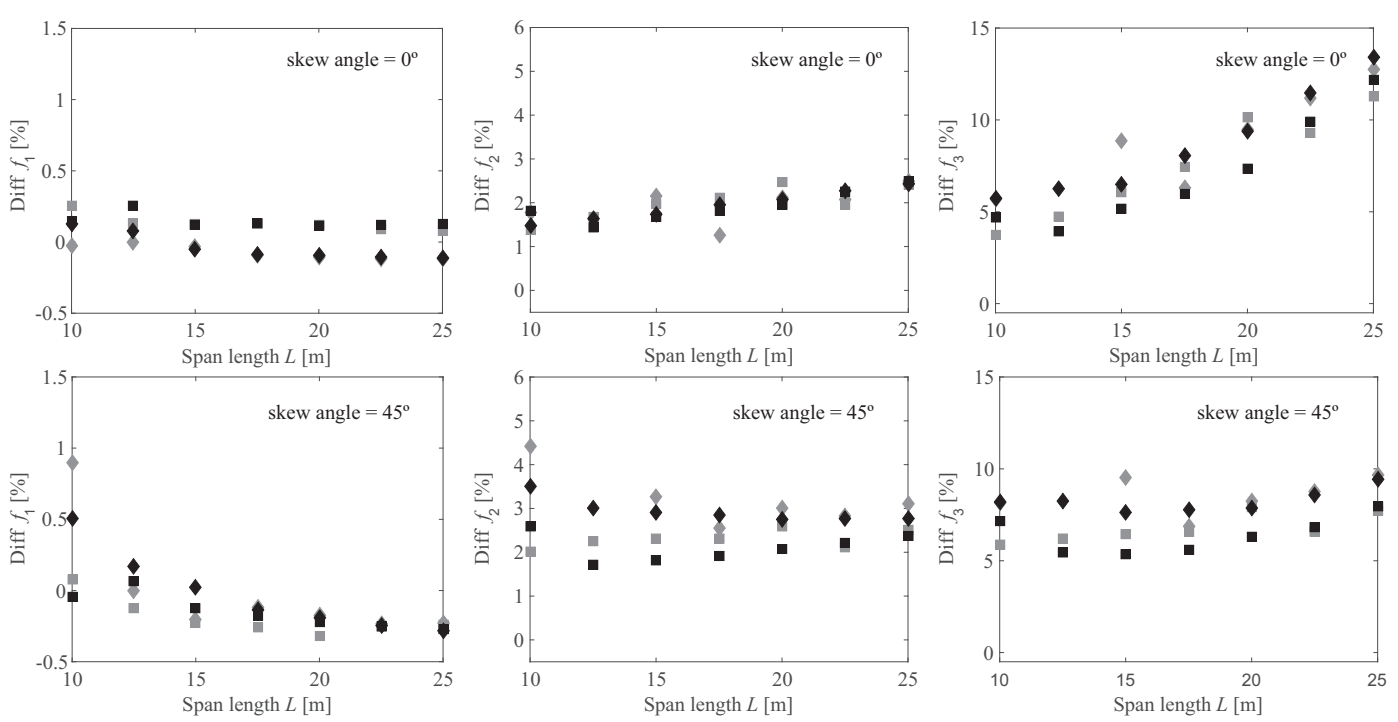

Figure 7: Differences in the prediction of the first three natural frequencies caused by the effect of the transverse bracing beams for the bridges with elastic supports. In grey, decks with $L / \delta<3000$; in black, decks with $L / \delta>3000$. Square markers, bridges with $N_{g}=6$; diamonds for the bridges with $N_{g}=5$.

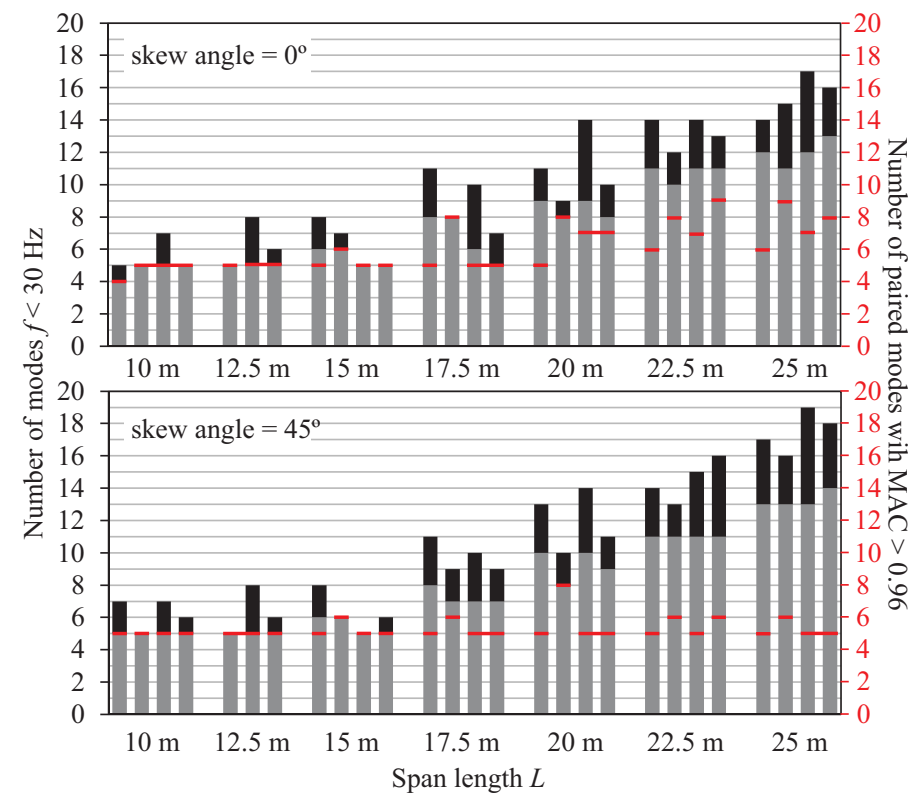

Figure 8: Number of modes of frequencies up to $30 \mathrm{~Hz}$ in the bridges of study considering $k_{v, d y n}=$ rigid. Grey columns: transverse beams included; black columns: transverse beams neglected.

values up to $10 \%$. For the fundamental mode the effect of the transverse bracing beams

is very mild, with maximum differences around $1 \%$. The effect of the bracing members 
is noticeably higher in oblique decks of moderate lengths when compared to straight structures. Furthermore, the frequency increase affecting the first torsion and transverse bending modes induced by the transverse elements accentuates in the case of decks with a lower number of longitudinal girders $\left(N_{g}=5\right)$ and similar $L / \delta$ ratios, especially in kewed configurations.

Regarding the bridge span, the main conclusion that can be extracted from the parametric analysis is that for the longest bridges the frequency variation induced by the bracing members is almost not affected by the number of longitudinal girders $N_{g}$ or by the deck flexural stiffness $L / \delta$, having these factors much more influence in the case of short or intermediate lengths. This conclusion applies regardless of the deck boundary conditions and the level of obliquity.

Fig 7 shows the frequency differences obtained in the bridges when considering the vertical stiffness of the neoprene bearings. As can be seen, the conclusions are similar to those corresponding to rigid supports cases. Therefore, the relation of the flexibility of the elastic supports with the effect of the transverse bracing beams on the prediction of the natural frequencies can be considered negligible in the range of vertical flexibilities typical for these structures. In general, the results of Fig 6 and Fig 7 show that the effect of the transverse bracing beams on the prediction of the natural frequencies of the first two modes (longitudinal bending and first torsion) appears to be more significant for the skewed decks, the shortest spans $(L=10 \mathrm{~m})$ and the smallest number of longitudinal girders $\left(N_{g}=5\right)$. The highest differences in these bridges have been found for the stiffness ratio $L / \delta$ in the range $2000-3000$, with values that attain $1.1 \%$ and $5.3 \%$ for the frequencies of the first and second mode, respectively. Only for the third mode the maximum frequency difference takes place for the longest span reaching $14 \%$ with limited effect of the deck flexural flexibility and the number of longitudinal girders.

Finally, the variation of the mode vectors caused by the introduction of the transverse bracing beams is evaluated in this work in terms of the Modal Assurance Criterion (MAC) [25], as an indicator of the level of correlation between the mode shapes predicted in any of the bridges of study by the numerical model that considers the transverse bracing beams and the modes obtained in the numerical model without them. MAC values vary from 0 to $1 ; \mathrm{MAC}=1$ implies perfect correlation between the two mode vectors (one vector is proportional to the other), while a close to zero MAC value indicates that the modes are not correlated (orthogonal modes). The results are summarized in Fig 8 for the bridges of study shown in Table 1 neglecting the vertical flexibility of the rubber bearings $\left(k_{v, d y n}=\right.$ rigid $)$. The columns of the plots indicate de number of modes below $30 \mathrm{~Hz}$ for the bridges that include the transverse bracing beams (in grey color), and also for the same bridges but neglecting these elements (in black). There are 4 columns associated to each span length, excepting the case $L=12.5 \mathrm{~m}$. These correspond to each of the bridges defined in the rows of Table 1. which appear in the plots from left to right. As can be seen the number of modes with frequencies below $30 \mathrm{~Hz}$, which are the ones required to perform a dynamic analysis as per European Standards [4], is in general lower for the bridges with transverse bracing beams due to the increase of the natural frequencies.

Fig 8 also provides information on the level of correlation between the mode shapes obtained in a certain bridge with the transverse beams and without them. The red horizontal line marked in each of the columns indicates the number of modes that are paired with a MAC value higher than 0.96 , implying a very high similarity of the modes. 
Since only the mode contributions up to $30 \mathrm{~Hz}$ are considered, the maximum number of paired modes cannot exceed the number of mode contributions below $30 \mathrm{~Hz}$ for the bridges that include the transverse beams (grey columns). As can be seen at least four modes in all the bridges are paired with MAC $>0.96$, which is in accordance with the observations illustrated in Fig 4 , the transverse bracing beams have a negligible influence on the curvatures and shapes of the first four modes. In the bridges with the shortest spans ( $L=10 \mathrm{~m}$ and $L=12.5 \mathrm{~m}$ ), most of the mode contributions below $30 \mathrm{~Hz}$ are paired with high accuracy. However, as the span length increases and so does the number of mode contributions below $30 \mathrm{~Hz}$, the ratio of paired modes with respect to the total number of modes below $30 \mathrm{~Hz}$ worsens. As can be seen in Fig 8 , for the longest spans the straight decks exhibit a better behaviour concerning the mode pairing. In other words, the effect of the transverse beams on the mode shapes is more noticeable as the span 315 length increases. For the sake of conciseness the results obtained when the flexibility of the elastic supports is considered are not shown in this work, since analogous tendencies are observed.

\subsection{Dynamic response under high-speed traffic}

The vertical response in terms of accelerations of the girder bridges is computed in the time domain at 25 points equally spaced over the track platform (Fig 9), and under the circulation of the ten HSLM-A trains defined in EC1 in a range of velocities between 200 and $420 \mathrm{~km} / \mathrm{h}$ in $3.6 \mathrm{~km} / \mathrm{h}$ steps. Two analyses per bridge deck have been performed, one is done including in the numerical model the transverse bracing beams as seen in Fig 3 and a second analysis is performed neglecting the presence of these elements. From these results envelopes of maximum acceleration at the deck platform have been computed for each numerical model, speed of circulation and postprocess point; these maximum acceleration levels take place in all the cases at the points located at midspan (points $\mathrm{C}_{1}$ to $\mathrm{C}_{5}$ ), showing the predominant contribution of modes with one half-sine wave along the load path on the vertical response.

The level of similarity between the acceleration envelope predicted with the transverse bracing beams $\left(a_{\text {max }}^{\text {brace }}\right)$ and the corresponding results obtained when these elements are not considered $\left(a_{\max }\right)$ are compared, at each circulating speed, as a relative difference according to the expression,

$$
\text { Relative difference }(\%)=\frac{a_{\max }-a_{\max }^{\text {brace }}}{a_{\max }^{\text {brace }}} \cdot 100 .
$$

Some of the results that exhibit the highest differences are shown in Fig.10 and 11 (for conventional bridges with $L / \delta<3000$ ) and in Fig.12 (for high-speed bridges with $L / \delta>3000$ ), grouped per span length. Starting with the bridges with lower flexural stiffness, in Fig 10 the plots on the left correspond to the relative differences predicted in the bridges of $10 \mathrm{~m}$ (top) and $15 \mathrm{~m}$ (bottom) of span length, with a $L / \delta$ ratio lower than 3000. For the span length of $10 \mathrm{~m}$ the highest differences have been obtained in the bridges with rigid supports; for the $15 \mathrm{~m}$ span bridges, in the cases with elastic supports. The four series represented in the plots correspond to the following cases: (i) black and grey markers are associated to bridges with 5 and 6 longitudinal girders, respectively; (ii) straight bridges are represented with square markers while the response of skewed structures is showed using diamonds. Furthermore, relative differences derived 


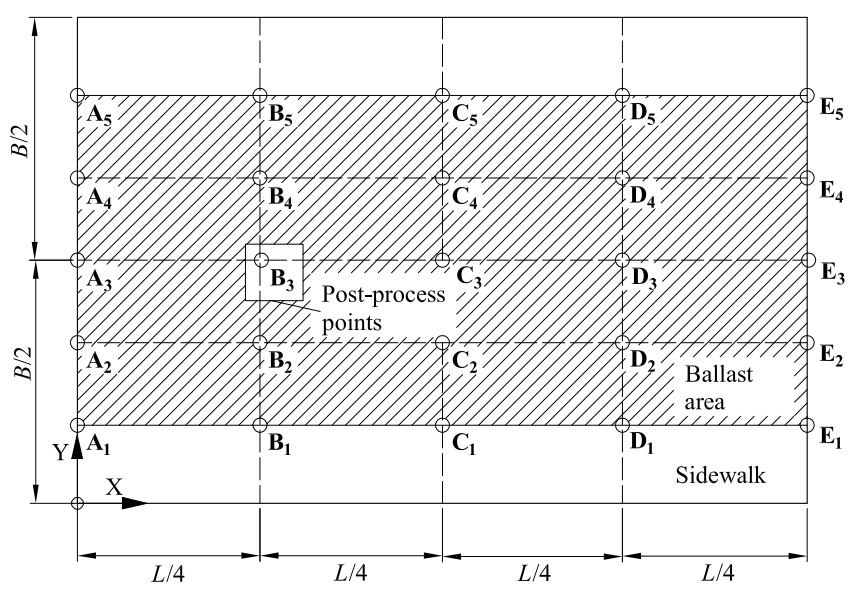

Figure 9: Post-process points for vertical accelerations.

from acceleration values below $3.5 \mathrm{~m} / \mathrm{s}^{2}$ have been excluded from the plot, since they are not relevant for the verification of the Serviceability Limit State (SLE) associated to traffic safety according to EC.

For a better understanding and interpretation of the relative differences shown in Fig 10, on the right side the envelopes of maximum vertical acceleration predicted in a particular bridge including the transverse bracing beams (black trace) and neglecting them (red trace) are plotted versus the speed of circulation. For each span length $(L=10$ and $L=15 \mathrm{~m}$ ) two representative bridge examples of the maximum positive and negative relative differences have been selected.

As can be seen in Fig 10, for the bridges of $10 \mathrm{~m}$ of span length the relative differences are mainly positive, implying that the introduction of the transverse bracing beams has a beneficial effect reducing the maximum vertical acceleration levels. The bridges most affected in this regard are skewed structures with the lowest number of longitudinal girders $\left(N_{g}=5\right)$, for a comparable overall flexural stiffness of the deck. Maximum reductions higher than $20 \%$ have been obtained for the skewed deck with 5 longitudinal girders. The acceleration envelopes of this particular case (right side of the figure), show more clearly the beneficial effect of the bracing beams in all the range of speeds, being the differences between the curves higher at speeds far from the resonance peaks. This is related to the frequency variations shown in the previous section: the resonances shown in the plot are associated to the fundamental mode, the frequency of which remains almost unaffected by the introduction of the transverse beams and, for that reason, the differences between models are lower at resonant speeds. For other deck configurations of the same length, the relative differences are significantly lower. Similar conclusions can be extracted from the $12.5 \mathrm{~m}$ case (not shown).

In the bridges of $15 \mathrm{~m}$ of span length also relative differences above $20 \%$ are obtained. However, as seen on the acceleration envelopes, the positive effect of the transverse bracing beams on the acceleration response is not so clear, and significant relative differences of negative sign appear in these cases. As it is well known, apart from the frequency variations caused by the introduction of the transverse bracing beams, there are other 

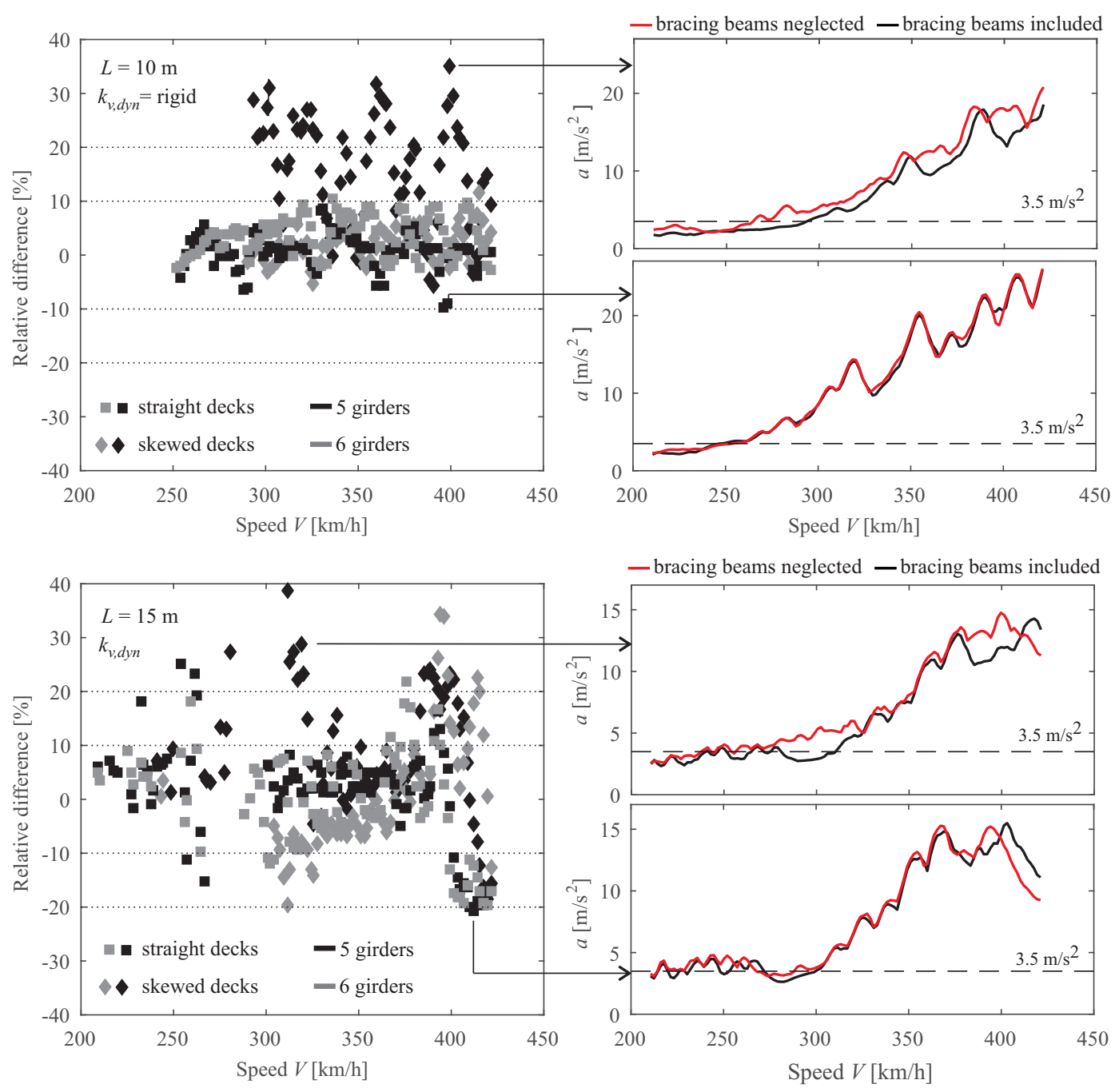

Figure 10: Relative differences in the prediction of the vertical acceleration envelopes caused by the effect of the transverse bracing beams for the bridges $L=\left[\begin{array}{ll}10 & 15\end{array}\right] \mathrm{m}$ with $L / \delta<3000$.

factors affecting the dynamic response, such as the number of mode contributions and their amplitude at both the post-processing points and along the loading path. The combination of all these factors influences the dynamic response in a way that it is more difficult to anticipate as the number of mode contributions included in the analysis increases. This type of phenomenon is also observed in other intermediate lengths, such as 17.5 (not shown) and $20 \mathrm{~m}$ (Fig 11).

For the longest analysed bridges of 22.5 (not shown) and $25 \mathrm{~m}$ (Fig 11) the stiffening effect of the bracing members is less relevant than in the previous cases. Furthermore, the correlation of the deck configuration and geometry in terms of the number of longitudinal girders or the degree of obliqueness with the effect of the transverse bracing beams is not 

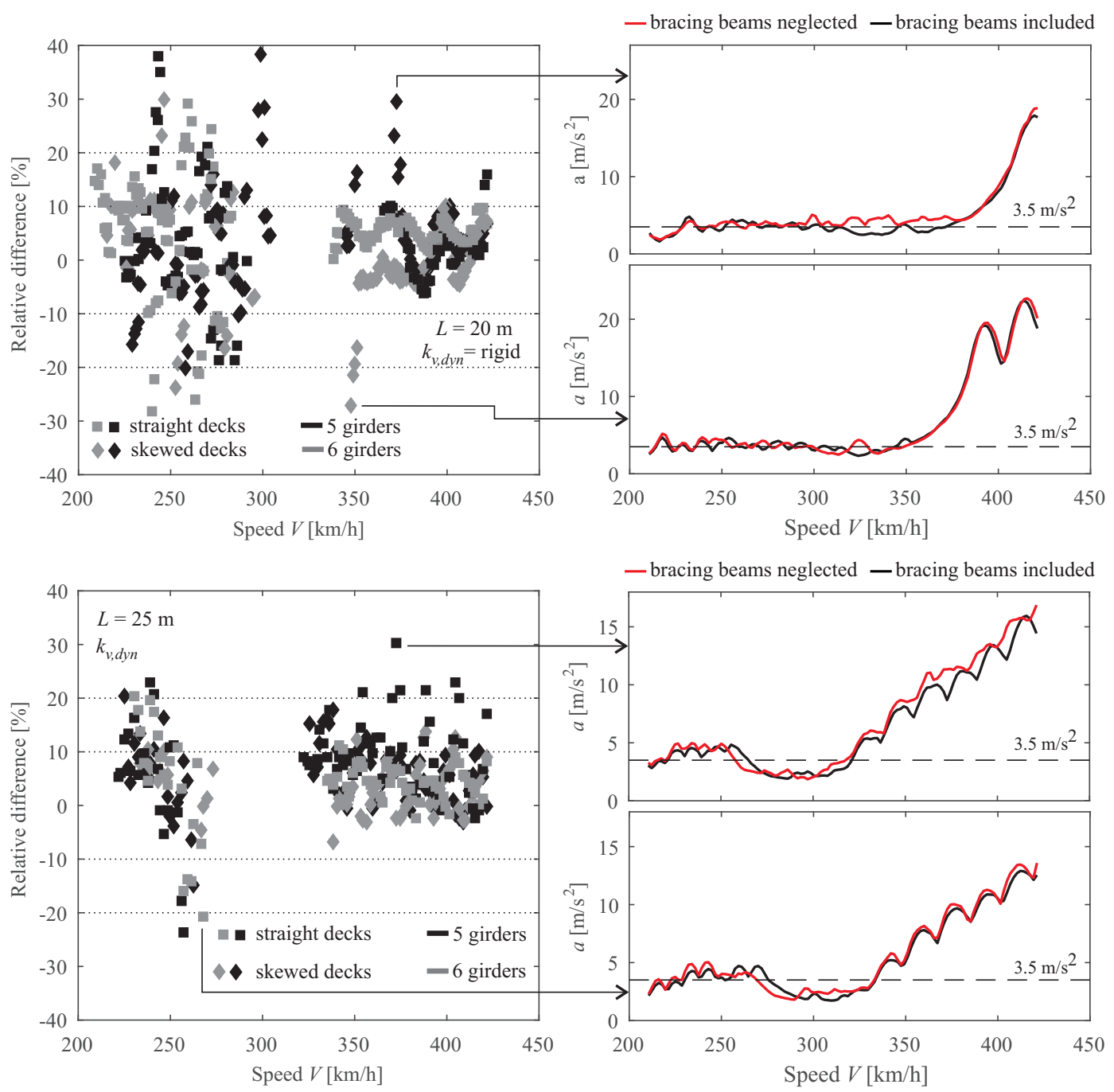

Figure 11: Relative differences in the prediction of the vertical acceleration envelopes caused by the effect of the transverse bracing beams for the bridges $L=[2025] \mathrm{m}$ with $L / \delta<3000$.

an issue, conversely to what occurs in the shorter structures.

The envelopes shown on the right side of Fig 10 and Fig 11 reveal considerably high levels, with peak values close to $20 \mathrm{~m} / \mathrm{s}^{2}$ for the shortest spans. It should be noted that these acceleration levels take place at very high speeds $(\mathrm{V}>350 \mathrm{~km} / \mathrm{h})$ and for the most flexible structures with $L / \delta<3000$, which in practice do not belong to high-speed lines.

Finally, in Fig 12 the acceleration maximum relative differences are once again represented for the same lengths for the bridges with flexural stiffness attributable to structures belonging to high-speed lines $(L / \delta>3000)$. The acceleration levels are significantly lower in the range of velocities analysed, as it should be expected, with maximum peak values below $10 \mathrm{~m} / \mathrm{s}^{2}$. The effect of the bracing members is only relevant at high speeds ( $\mathrm{V}>300$ 
$390 \mathrm{~km} / \mathrm{h}$ ), unlike in the previous case. Nevertheless, the following can again be concluded: (i) the beneficial effect of the bracing members is especially evident for the shorter spans (10 and $12.5 \mathrm{~m}$ ) and for the skewed cases with a low number of longitudinal girders (5); (ii) the maximum response of the longest bridges $(20$ to $25 \mathrm{~m}$ ) is less affected by the presence of these elements and, in any case, the number of longitudinal girders or the 395 degree of obliqueness is not an issue in these cases.
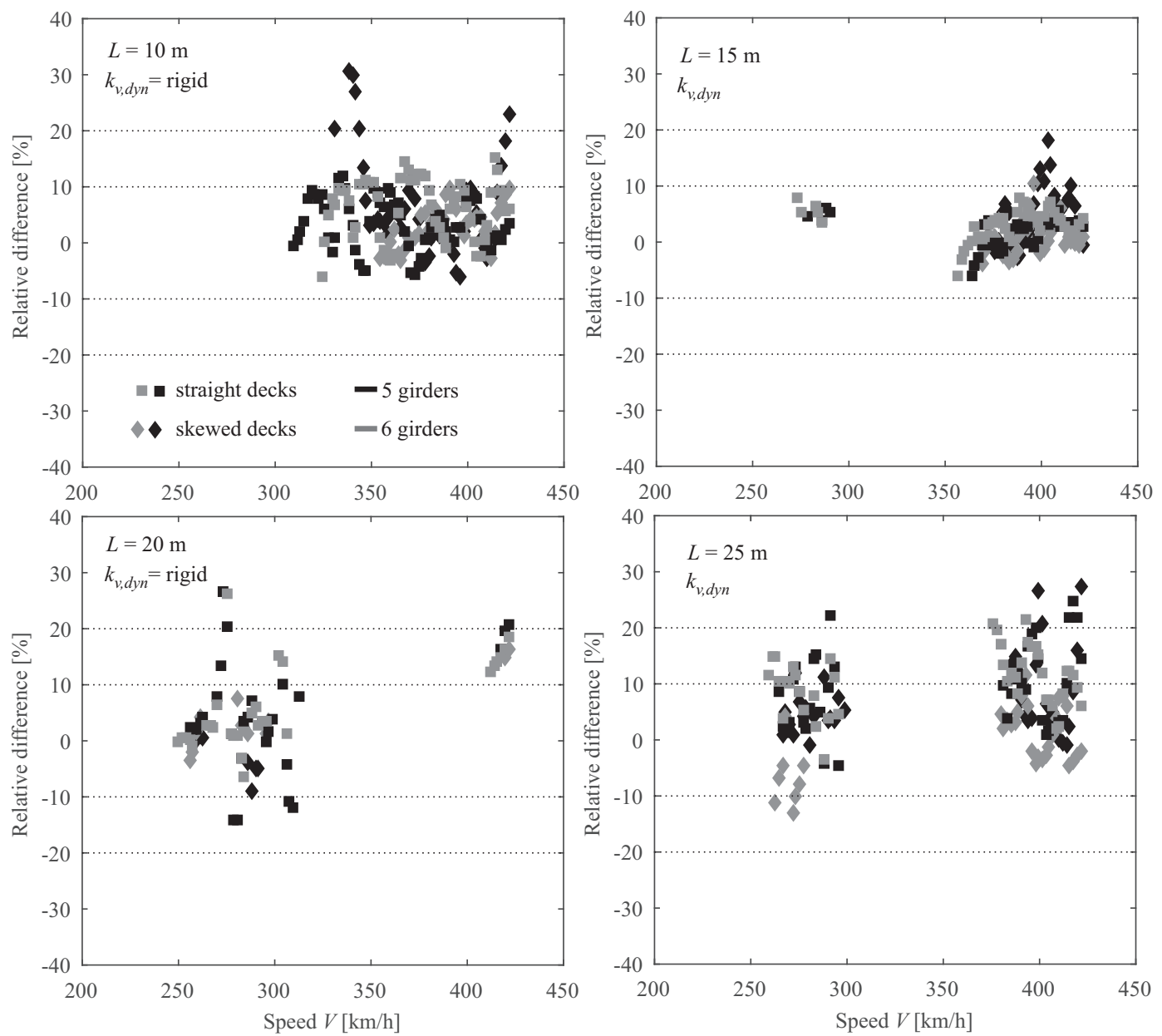

Figure 12: Relative differences in the prediction of the vertical acceleration envelopes caused by the effect of the transverse bracing beams for several bridges with $L / \delta>3000$.

It is also important to notice that Fig 10, 11 and 12 show, indistinctly, the results associated to bridges that include or neglect the flexibility of the elastomeric bearings in the numerical models. In the figures the choice of one approach or another is only made for illustrative purposes, since the relation of the supports flexibility with the effect of the transverse beams on the acceleration response is not relevant in the range of realistic vertical flexibilities of these supporting elements. 


\section{Case study: Arroyo Bracea I bridge}
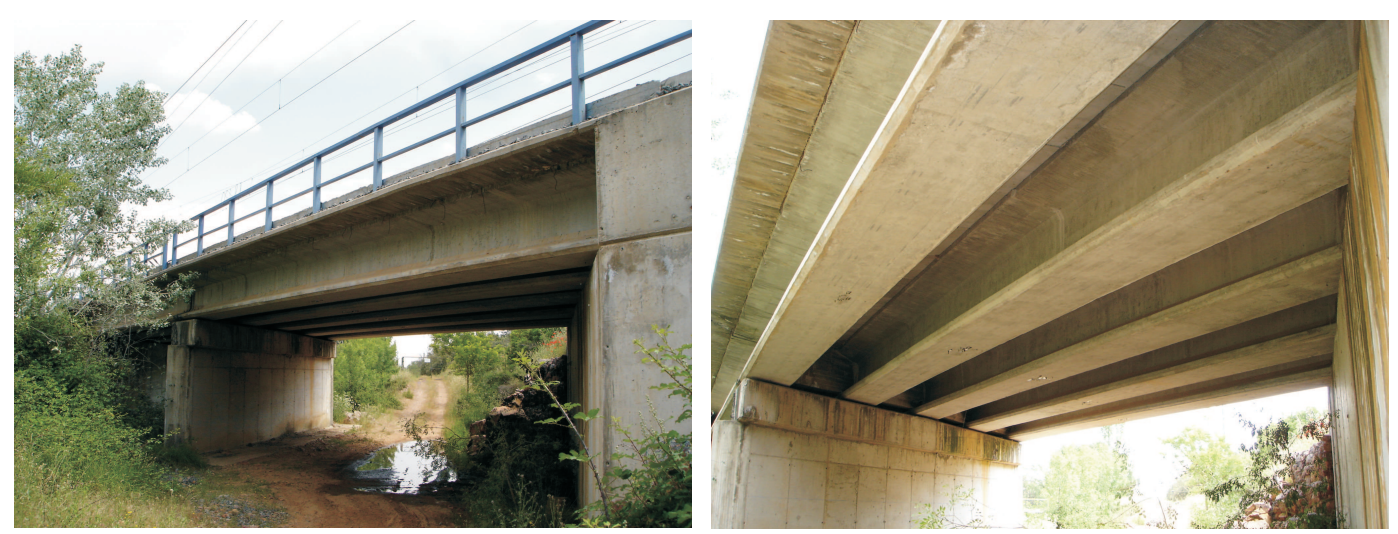

Figure 13: Arroyo Bracea I bridge.

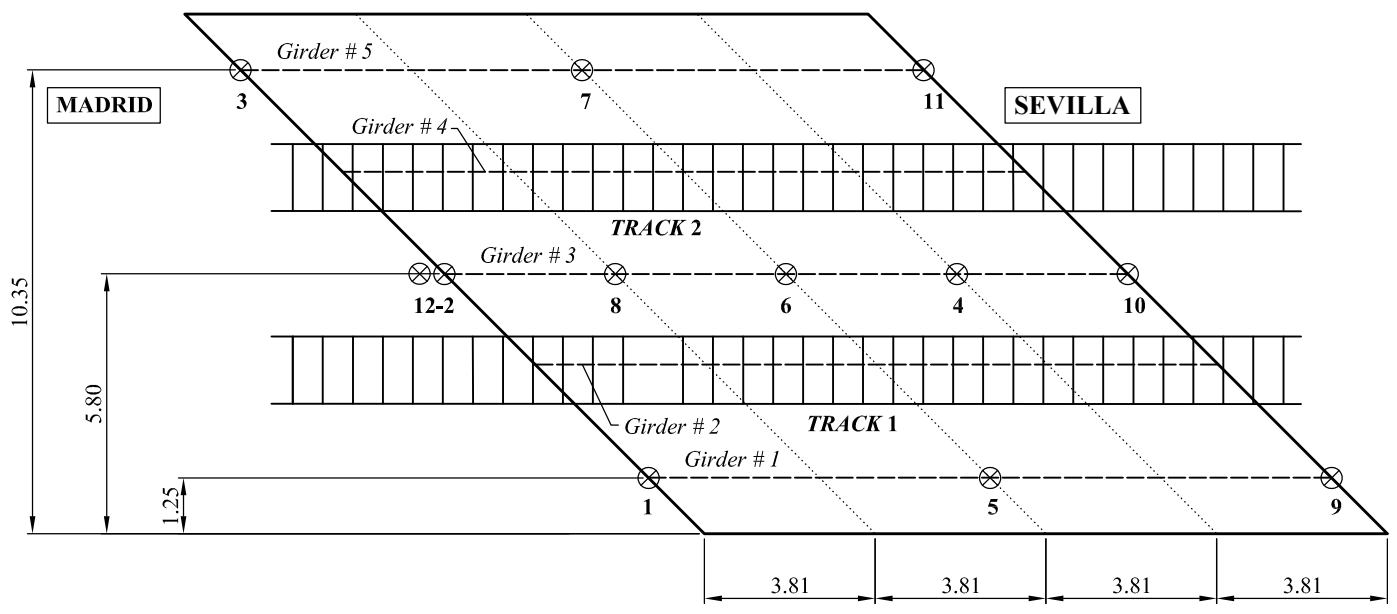

Figure 14: Sensor location in Arroyo Bracea I bridge

The experimental campaign performed in the past by the authors on a short SS girder bridge [18] is used in this section to validate the previous observations regarding the effect of the transverse bracing beams on the dynamic behaviour of these structures. The structure under study, designated as Arroyo Bracea I, is a double ballasted track railway bridge that belongs to the first high-speed railway line opened in Spain in 1992, Madrid-Seville (see Fig 13). It is composed by two identical SS bays with a span length of $15.25 \mathrm{~m}$, and crosses the Bracea stream with a $45^{\circ}$ skew angle. Each deck consists of a

$41025 \mathrm{~cm}$ thick, $11.6 \mathrm{~m}$ width concrete slab resting over five prestressed concrete longitudinal I girders. The girders rest on the supports through laminated rubber bearings. As per the substructure, the bridge deck is supported on reinforced concrete abutments in its outermost sections and on a pile foundation in the inner ones. At the supports position, 


\begin{tabular}{|c|c|c|c|c|c|c|c|c|c|}
\hline Spal & $h[\mathrm{r}$ & $h_{t}[m$ & & Longitu & dinal & & $\mathrm{Ma}$ & Suppor & $L /$ \\
\hline 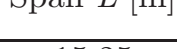 & & & $N_{g}$ & $d_{g}[\mathrm{~m}]$ & $h_{g}[\mathrm{~m}]$ & $I_{h}\left[\mathrm{~m}^{4}\right]$ & {$[\mathrm{kg} /$} & $k_{v, \text { dyn }}[N / 1$ & \\
\hline 15.25 & 0.27 & 0.77 & 5 & 2.275 & 1.05 & 0.08802 & 28355 & $1.4 \mathrm{E} 9$ & 3847 \\
\hline
\end{tabular}

Table 2: Main properties of Bracea I bridge

the ends of the longitudinal girders are tied to one another with a cast-in-situ transverse 415 bracing beam. Table 2 shows a general description of the geometry and the updated mechanical properties used in the numerical models. More details can be found in [18].

The experimental campaign on this bridge, performed in July 2016, included a dynamic characterisation of the soil and of the structure. For a detailed description of the experimental tests results the reader is referred to [18]. As regards the structure, the acceleration response was measured at 11 points of the lower flange of the pre-stressed concrete girders (points 1-11 in Figure 14) and at the abutment upper horizontal surface close to the girders support (point 12 in Figure 14). Endevco model 86 piezoelectric accelerometers with a nominal sensitivity of $10000 \mathrm{mV} / \mathrm{g}$ and a low frequency limit of $0.1 \mathrm{~Hz}$ are installed in the aforementioned locations.

425 5.1. Modal parameters

The ambient vibration data registered during the experimental campaign was used for the identification of the modal parameters of the bridge by state-space models, using MACEC software [26]. Table 3 shows the damping ratios and natural frequencies of the five identified modes $\left(f_{\text {exp }}\right)$, where the lowest ones in frequency order correspond to the 430 first longitudinal bending, first torsion and first transverse bending mode shapes. The Modal Phase Collinearity (MPC) [27] provided in Table 3 shows the consistency of the identified structural modal parameters, with values higher than 0.95 .

\begin{tabular}{cccccccc} 
Mode number & $f_{\text {exp }}[\mathrm{Hz}]$ & MPC $[-]$ & $\xi_{\text {exp }}[\%]$ & $f_{\text {num }}[\mathrm{Hz}]$ & $f_{\text {num }, \text { brace }}[\mathrm{Hz}]$ & $\mathrm{MAC}_{\text {exp,num }}[-]$ & MAC $_{\text {exp,brace }}$ \\
\hline 1 & 9.25 & 0.99 & 2.0 & 9.13 & 9.15 & 0.95 & 0.96 \\
2 & 10.63 & 0.97 & 1.61 & 9.86 & 10.15 & 0.93 & 0.93 \\
3 & 12.75 & 0.99 & 1.30 & 11.83 & 12.73 & 0.95 & 0.96 \\
4 & 17.92 & 0.99 & 0.80 & 16.71 & 18.77 & 0.96 & 0.95 \\
5 & 24.57 & 0.99 & 0.95 & 24.62 & 28.00 & 0.98 & 0.96
\end{tabular}

Table 3: Experimental and numerical natural frequencies, experimental modal damping ratios, $\mathrm{Au}-$ toMAC and MPC values.

The table also shows the numerical natural frequencies predicted by the updated FE model using two approaches: neglecting the transverse bracing beams of the bridge $435\left(f_{\text {num }}\right)$ and including them $\left(f_{\text {num }}^{\text {brace }}\right)$. MAC numbers are also provided. As can be seen, the correspondence between the experimental measurements and the numerical predictions is reasonably accurate in terms of frequencies and mode shapes. The presence of the transverse bracing beams induces a deck stiffening effect which affects to a greater extent the modes leading to a significant transverse bending of the deck (in this case, all the modes different from the fundamental). In virtue of this effect, the prediction of the second and third frequencies, corresponding to the first torsion and first transverse bending modes, is significantly improved when the transverse beams are included in the 
numerical model. Conversely, the prediction of the fifth natural frequency worsens with respect to the model without transverse beams. As a result, the numerical model that neglects the transverse bracings predicts the deck natural frequencies with errors lower than $8 \%$ for the first five modes. When the transverse beams are included the errors are lower than $5 \%$ for the first four ones; however the prediction of the fifth natural frequency worsens significantly, with an error of $14 \%$. The frequency differences between the two numerical models are in accordance with the observations of Section 4.1 for similar span 450 lengths and $L / \delta$ ratios.
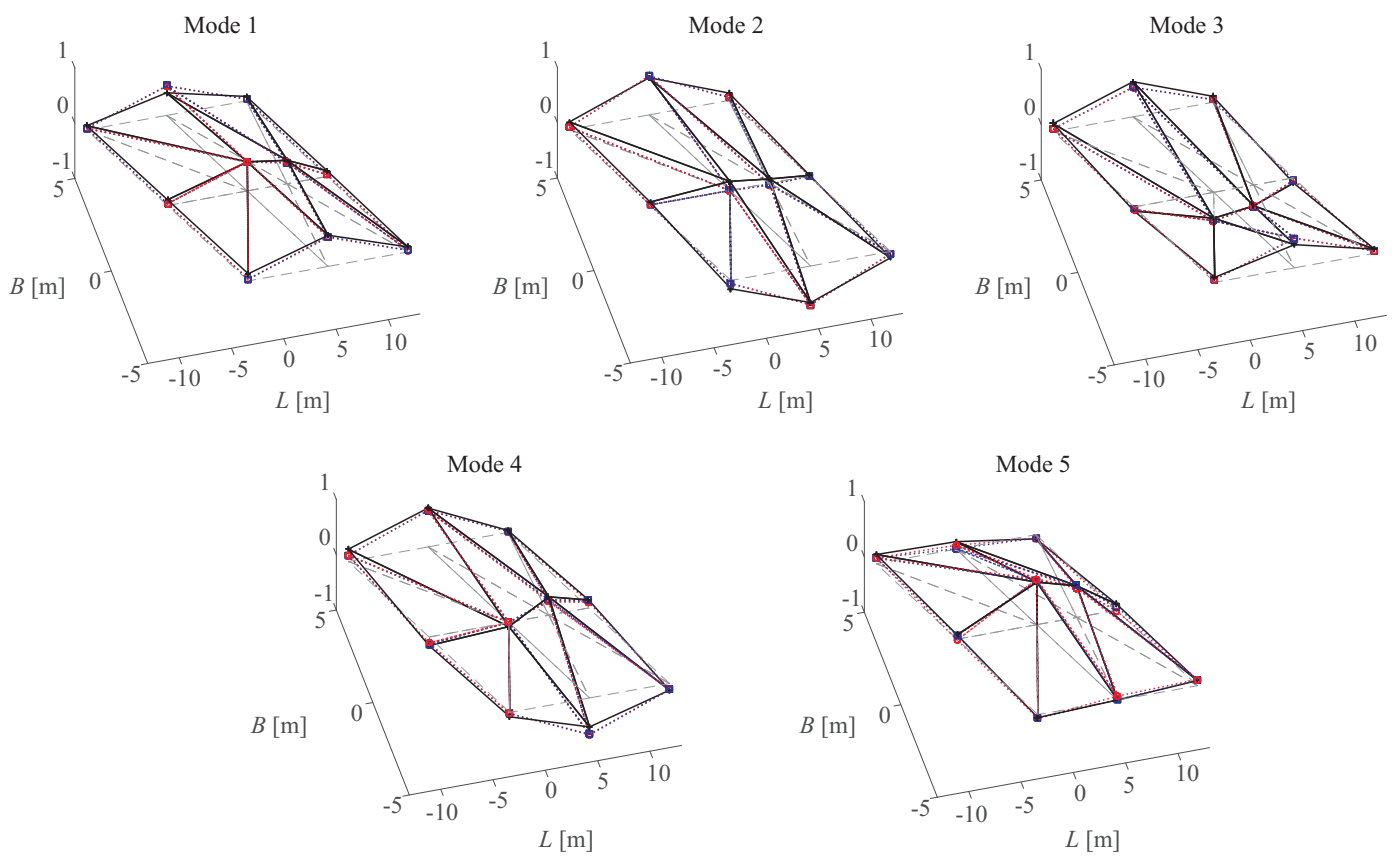

Figure 15: Experimental (black solid line) vs. numerical with transverse bracing beams (red dotted line) and numerical without transverse bracing beams (blue dotted line) first five identified mode shapes. Undeformed shape (dashed grey line).(For best interpretation of this figure traces, the reader is referred to the web colour version of this article.)

Fig 15 shows the first five mode shapes of Arroyo Bracea I bridge. As the mode number increases the shape is not clearly distinguishable due to the reduced number of measurement points in the experimental campaign with respect to the mode wavelength. However, according to the numerical predictions, the fourth and fifth mode correspond to 455 transverse bending mode shapes of increasing number of half sine waves. The influence of the transverse bracing beams on the eigenforms is almost negligible, as can be derived from the observation of the MAC values. Both numerical approaches provide MAC values higher than 0.95 for all the modes different from the first torsion one, in which the MAC value attains 0.93 and is not improved by the presence of the transverse bracing ${ }_{460}$ elements, unlike the torsion natural frequency which is better captured when including these elements. 


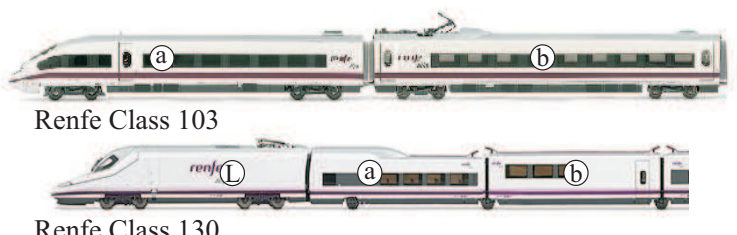

Renfe Class 130

\begin{tabular}{|c|c|c|c|c|c|c|c|c|}
\hline Train & \multicolumn{5}{|c|}{ Renfe S103 } & \multicolumn{3}{|c|}{ Renfe S130 } \\
\hline & $d[\mathrm{~m}]$ & {$[\mathrm{kN}$} & & $\boldsymbol{d}[\mathrm{m}]$ & $\boldsymbol{P}[\mathrm{kN}$ & & $\boldsymbol{d}[\mathrm{m}]$ & $\boldsymbol{p}[\mathrm{kN}]$ \\
\hline Axle 1 & 3.51 & 147 & Axle 21 & 4.9 & 145 & Axle 1 & 4.4 & 180 \\
\hline Axle 2 & 2.5 & 147 & Axle 22 & 2.5 & 145 & Axle 2 & 2.8 & 180 \\
\hline Axle 3 & 14.875 & 141 & Axle 23 & 14.875 & 155 & Axle 3 & 7.85 & 180 \\
\hline Axle 4 & 2.5 & 141 & Axle 24 & 2.5 & 155 & Axle 4 & 2.8 & 180 \\
\hline Axle 5 & 4.9 & 149 & Axle 25 & 4.9 & 154 & Axle 5 & 6.67 & 156 \\
\hline Axle 6 & 2.5 & 149 & Axle 26 & 2.5 & 154 & Axle 6 & 8.97 & 161 \\
\hline Axle 7 & 14.875 & 149 & Axle 27 & 14.875 & 155 & Axle 7 & 13.14 & 170 \\
\hline Axle 8 & 2.5 & 149 & Axle 28 & 2.5 & 155 & Axle 8 & 13.14 & 167 \\
\hline Axle 9 & 4.9 & 149 & Axle 29 & 4.9 & 148 & Axle 9 & 13.14 & 159 \\
\hline Axle 10 & 2.5 & 149 & Axle 30 & 2.5 & 148 & Axle 10 & 13.14 & 166 \\
\hline Axle 11 & 14.875 & 143 & Axle 31 & 14.875 & 153 & Axle 11 & 13.14 & 166 \\
\hline Axle 12 & 2.5 & 143 & Axle 32 & 2.5 & 153 & Axle 12 & 13.14 & 170 \\
\hline Axle 13 & 4.9 & 134 & & & & Axle 13 & 13.14 & 166 \\
\hline Axle 14 & 2.5 & 134 & & & & Axle 14 & 13.14 & 170 \\
\hline Axle 15 & 14.875 & 131 & & & & Axle 15 & 13.14 & 166 \\
\hline Axle 16 & 2.5 & 131 & & & & Axle 16 & 8.97 & 163 \\
\hline Axle 17 & 4.9 & 129 & & & & Axle 17 & 6.67 & 180 \\
\hline Axle 18 & 2.5 & 129 & & & & Axle 18 & 2.8 & 180 \\
\hline Axle 19 & 14.875 & 135 & & & & Axle 19 & 7.85 & 180 \\
\hline Axle 20 & 2.5 & 135 & & & & Axle 20 & 2.8 & 180 \\
\hline
\end{tabular}

Figure 16: Trains coach distribution and axle schemes

\subsection{Train-induced vibrations}

During the experimental campaign performed on Bracea I bridge the deck vertical response was registered under the circulation of several high-speed trains. Two of these trains, RENFE Class 103 (ICE 3 or S103) and 130 (Talgo 250 or S130) are particularly interesting due to their speeds of circulation: the circulating velocity of S103 is $279 \mathrm{~km} / \mathrm{h}$, in the vicinity of the theoretical third resonance speed of the fundamental mode caused by the axle passengers cars $(275 \mathrm{~km} / \mathrm{h})$; and $\mathrm{S} 130$ circulates at $247 \mathrm{~km} / \mathrm{h}$, which is also close to a second resonance speed of one of the modes most affected by the transverse

470 bracing beams, the second mode $(251.4 \mathrm{~km} / \mathrm{h})$. This resonance is also associated to the axle distance in the passengers cars. The bridge response under the circulation of S103 and S130 trains is presented below.

RENFE Class 103 is a train with distributed traction and powered bogies located in alternate carriages, being the coach distribution a-6xb-a (eight cars, with an integrated driver and passenger car at each end). RENFE Class 130 has two power cars, with a coach distribution L-a-9xb-a-L. Figure 16 shows the axle schemes and coach distribution of both trains.

Fig 17 and 18 show, respectively, the vertical acceleration response under the passage 
of S103 and S130 trains at different points of the deck, in particular points 5 (mid-

span girder number 1), 6 (mid span girder number 3) and 10 (second abutment girder number 3). The response is plotted in the time domain (first row of the figures) and frequency domain (last row of the figures). In all the plots the experimental signal, plotted in solid black trace, is filtered applying a two third-order Chebyshev filter with high-pass and low-pass frequencies of $1 \mathrm{~Hz}$ and $30 \mathrm{~Hz}$. The numerical predictions, plotted 485 in blue for the model neglecting the transverse bracing beams and in red colour for the numerical response including them, are calculated by mode superposition including modal contributions up to $30 \mathrm{~Hz}$ as per European Standards [4].

As can be seen from the frequency domain plots the vertical acceleration response of the bridge is caused by several mode contributions apart from the longitudinal bending

490 one. The length to width aspect ratio along with the deck obliquity contribute to a dynamic response different from that of a beam type structure. In addition to the peaks associated to structural modes, the frequency contributions associated to the excitation and corresponding to the bogie passing frequency $(4.5 \mathrm{~Hz}$ for S103 in Fig 17 and 5.2 $\mathrm{Hz}$ for S130 in Fig (18) are visible in all the measurement points. The amplitude of the 495 excitation peaks is higher for the S130, which can be attributable to its particular axle scheme, with a lower number of axle per passenger car when compared to the bogie distribution of S103 (Fig [16).

In Fig 17 the resonance induced by the passage of S103 train is particularly clear in the time history plots, specially at points 5 and 6 , due to the progressively increasing ac${ }_{500}$ celeration response of the structure with the axles passage. Additionally, in the frequency domain plots the peak associated to the resonant mode (the fundamental) predominates when compared to the other frequency contributions. By contrast however, the previously mentioned characteristics of a resonance situation are not so well distinguishable in Fig 18. In the frequency spectrum the peak associated to torsion is more perceptible 505 at point 5 than in the other records, which is in accordance with the sensor location. However, its amplitude is not predominant and the participation of several modal contributions different from the resonant mode are clearly perceptible. This fact can be attributed to the presence of a theoretical cancellation of the resonance condition in the vicinity of the circulation speed of S130 28, 29]. In addition, the frequencies associated to the vehicle system (car-bodies masses), as it is the case of the vertical frequency of the primary suspension system $n_{p}$, which reaches $9.64 \mathrm{~Hz}$ for S130 train passenger coaches bogies [30], is close to the torsion mode frequency. Therefore a certain reduction due to vehicle-structure interaction should be expected. In the previous case, $n_{p}=5.84 \mathrm{~Hz}$ for S103 train [30], therefore the interaction with the vehicle should be much lower.

Fig 17 and 18 reveal that the numerical predictions are reasonably accurate with both models, especially for the sensors located at mid-span (points 5 and 6 ) and in the frequency range 1-13 Hz, which is the frequency interval of the first three modes of the structure. The models predictions differ to a higher extent at higher frequencies, and this is consistent with the frequency variations observed in Table 3. The frequency peaks associated to the excitation (the bogie passing frequency) and also the corresponding to the first structural mode are well predicted by both numerical models. Regarding the contribution of the fundamental mode, both models predict the amplitude of this peak with a similar level of accuracy, leading to a certain overestimation with respect to the experimental measurements at points 5 and 6 , which is more visible at resonance (Fig 17). This is in accordance to the train-bridge interaction effects, that are not considered in 

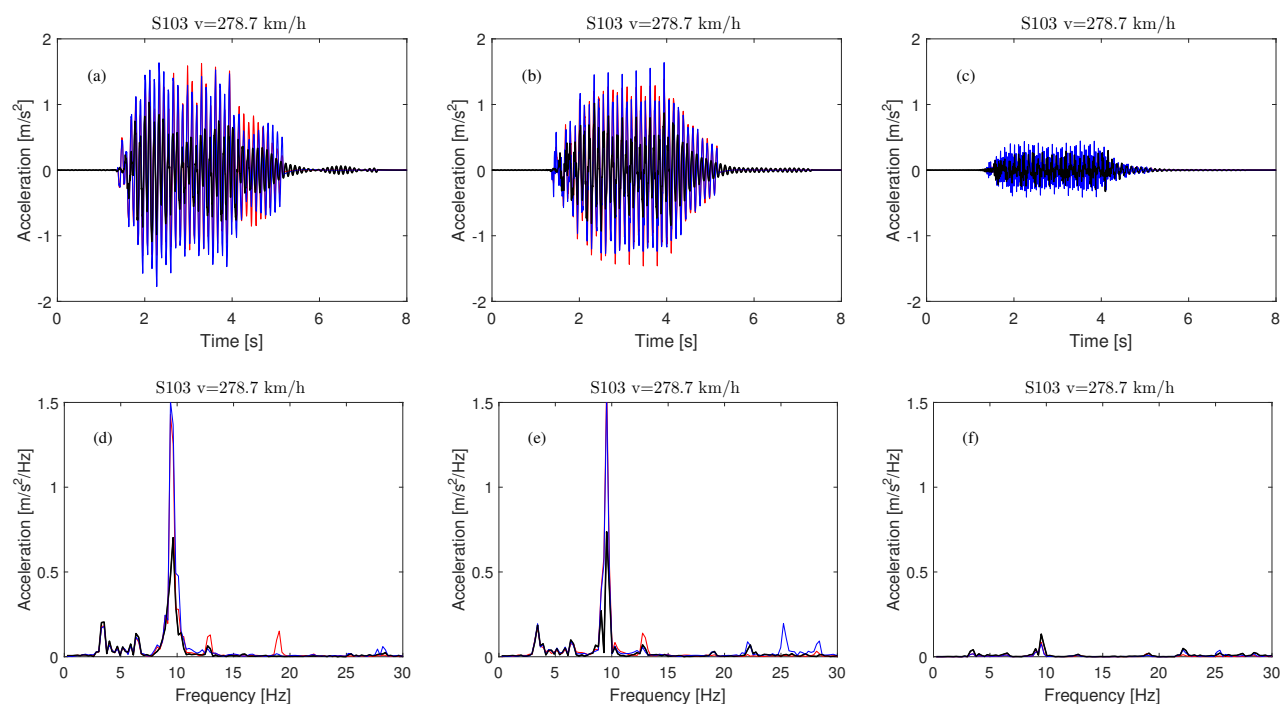

Figure 17: Time history (a,b,c) and frequency content (d,e,f) of the acceleration at point 5 (a,d), point 6 (b,e) and point 10 (c,f) induced by S103 Renfe class train: experimental (black line), numerical without transverse bracing beams (blue line) and numerical with transverse bracing beams (red line).(For best interpretation of this figure traces, the reader is referred to the web colour version of this article.)
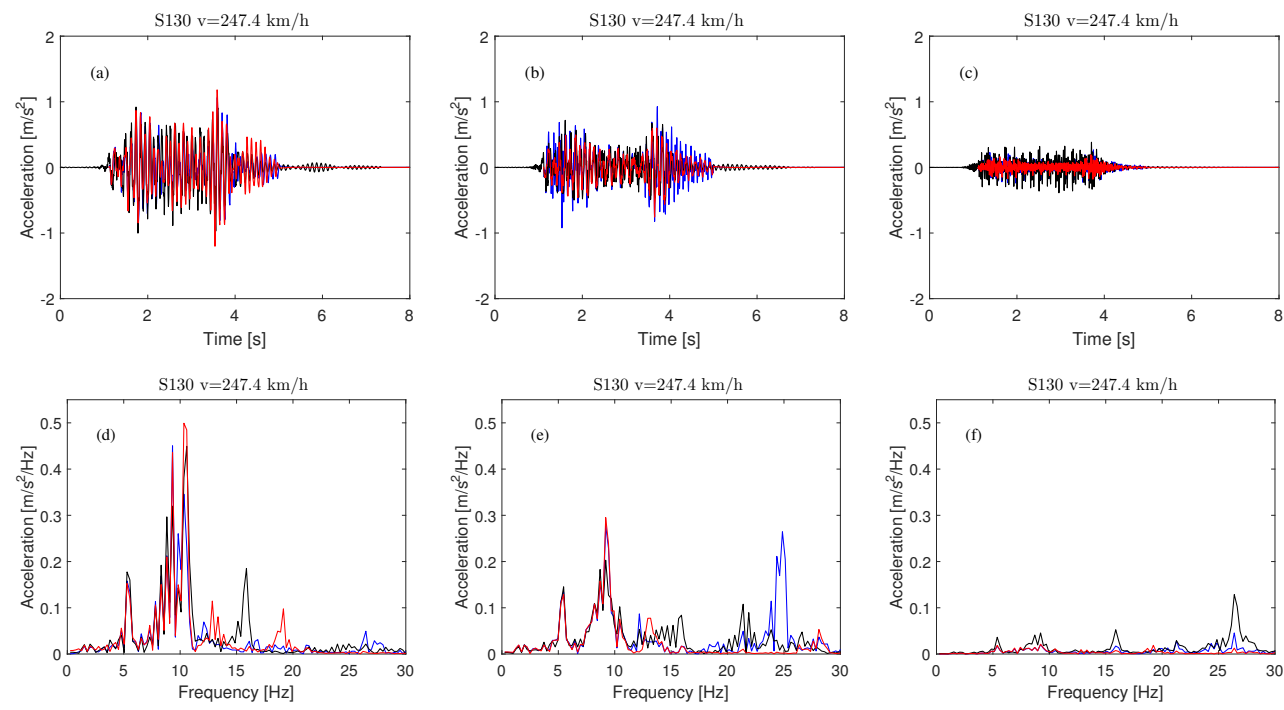

Figure 18: Time history $(\mathrm{a}, \mathrm{b}, \mathrm{c})$ and frequency content $(\mathrm{d}, \mathrm{e}, \mathrm{f})$ of the acceleration at point $5(\mathrm{a}, \mathrm{d})$, point 6 (b,e) and point 10 (c,f) induced by S130 Renfe class train: experimental (black line), numerical without transvere bracing beams (blue line) and numerical with transverse bracing beams (red line).(For best interpretation of this figure traces, the reader is referred to the web colour version of this article.)

the numerical models and may cause a reduction of the dynamic response, and also with the non-linear nature of structural damping, as stated in previous works [8, 31]. At point 
10, where the previous effects are less significant due to the lower level of vibrations, the presence of the transverse bracing beams in the numerical model does not improve the predictions with respect to the model without them. At the abutments other effects could prevail, such as soil-structure interaction that is not considered in the models, or the distributive effect of the track components, which is is included in the numerical models in a simplified approach. In Fig[18, where the contribution of the torsion mode is more perceptible in the frequency spectrum of point 5 , it is clearly seen that the model with transverse bracing beams predicts this peak more accurately than the model without them. This fact can be explained by the better correspondence in terms of torsion frequency with the experimental measurements.

In general, at the points far from the abutments (point 5 and 6 ) both numerical models tend to overestimate the dynamic response, specially at resonance. Close to 540 the abutments (point 10) the acceleration response is, in general, underestimated by the numerical models with the exception of the results at point 10, shown in Fig 17 . where the acceleration predicted by the model with transverse bracings in the time domain shows a similar amplitude with respect to the experimental response. This underestimation effect has been observed for the other trains passages recorded during

545 the experimental campaign, which none of them induced resonance on the structure. It may be concluded that the consideration of the transverse bracing elements in the numerical model of the bridge deck improves the prediction of the forced response when modes such as the first torsion or transverse bending modes contribute significantly to the response. Nevertheless, in the particular case of Arroyo Brace I bridge, with ${ }_{550}$ an intermediate length, the differences in the maximum vertical acceleration predicted values are not determinant, as expected from the conclusions derived from section 4.2 .

\section{Conclusions}

The dynamic behaviour of short SS pre-stressed concrete girder bridges and the effect of transverse beams bracing the longitudinal girders at the deck end sections is inves-

555 tigated in this work. In particular, the stiffening action of these elements and their influence on the modal parameters of the structure and on the train induced vibration response is addressed. First, a comprehensive sensitivity analysis is designed and performed with the aim of evaluating the effects of the aforementioned elements covering a representative portion of realistic girder bridges which exist nowadays in conventional 560 and high-speed railway lines. To this end, a representative ensemble of 108 double track SS girder bridges, with span lengths ranging from $10 \mathrm{~m}$ to $25 \mathrm{~m}$ and, different deck obliquity levels, number of longitudinal girders, deck flexural stiffness and flexibility of the elastic bearings, is predesigned for this study. Subsequently, the modal behaviour and the maximum expectable vertical acceleration response under high-speed traffic is

565 computed numerically, following the European prescriptions (Eurocodes), and the effects of the transverse bracing elements and the correlation with other deck parameters is evaluated. The main conclusions of the study are:

- The presence of transverse bracing beams leads to an increment of the natural frequencies of the structure, which is more noticeable for the mode shapes with significant transverse deformation, such as the first torsion and the first transverse 
bending modes. In the first three modes of all the analyzed bridges, which correspond to a first longitudinal bending, first transverse bending and first torsion modes, maximum increments reach $1 \%, 5 \%$ and $14 \%$, respectively.

- Oblique decks of short to moderate span lengths (10-12.5 m) are the most affected by the frequency increase caused by the transverse bracing beams. Furthermore, in the cited deck configurations this effect accentuates for the first torsion and first transverse bending mode if the smallest number of longitudinal girders is considered (5) for a similar deck flexural stiffness. Conversely, for the longest bridges the frequency variations induced by the bracing members remain roughly unaffected by the deck parameters (number of girders or deck flexural stiffness).

- The relation of the flexibility of the elastic supports with the effect of the transverse bracing beams on the prediction of the natural frequencies is not relevant in a realistic range of vertical flexibilities for the bearings.

- The variation of the mode shapes of the bridge with the introduction of the transverse bracing beams is more noticeable as the frequency and span length increase. In all the bridges, MAC values above 0.96 have been obtained for the first four mode shapes of the decks including and neglecting the transverse beams in the numerical model.

- In terms of expectable maximum vertical accelerations at the deck level under the passage of high-speed trains, a beneficial effect of the presence of the transverse beams is evident for the shortest spans (10 and $12.5 \mathrm{~m}$ ), especially in the case of skewed decks with a small number of longitudinal girders. For the longest spans the maximum acceleration response is not especially affected by these elements, and the deck obliqueness or number of longitudinal girders does not modify this latter observation.

The previous conclusions have been validated with the measurements from an experimental campaign performed on a SS girder bridge of moderate span $(L=15.25$ $\mathrm{m}$ ) belonging to a high-speed railway line in Spain. The variations of the natural frequencies and mode shapes caused by the introduction of the transverse bracing beams in the numerical models are of the same order than the ones observed for the ensemble of girder bridges with similar characteristics. Due to the stiffening effect of the transverse beams, the calibration of the first torsion mode of the bridge is more accurate, in terms of frequencies, when the transverse bracing beams are included in the numerical model. However, the influence of these elements on the prediction of the vertical acceleration levels is not significant, as observed in the studied bridges of moderate spans.

According to the previous results, a general recommendation can be derived for the modelling of girder bridges: in short $(10-12.5 \mathrm{~m})$ and oblique bridges with a low number of longitudinal girders, the introduction of the transverse beams in the numerical models is beneficial for model updating since a more accurate calibration of the natural frequencies is expected. As indicated above, this effect is more relevant for modes that lead to a significant transverse bending of the deck, 
as is the case of the first torsion mode. As a result the prediction of the traininduced vibrations can be improved in situations where resonances of these modes are expected.

\section{Acknowledgements}

The authors would like to acknowledge the financial support provided by (i) the Spanish Ministry of Economy and Competitiveness under the research project [BIA201675042-C2], (ii) the Andalusian Scientific Computing Centre (CICA) and (iii) Universitat ${ }_{620}$ Jaume I under the research project [UJI-A2018-06].

\section{References}

[1] ERRI-D-214/RP9, Ponts Rails pour vitesses $>$ 200km/h. Rapport final, European Committee for Standardization, Brussels, 2000.

[2] UIC, Union Internationale des Chemins de Fer.Code UIC 776-1R. Charges a prendre en consideration dans le calcul des ponts-rails, UIC, 1979.

[3] UIC, Union Internationale des Chemins de Fer.Code UIC 776-2R.Exigences dans la conception des ponts-rails liées aux phénomenes dynamiques d'interaction véhicule-voie-pont, UIC, 2009.

[4] CEN, Eurocode: Basis of structural design. Annex A2: Application for bridges. Final version, European Committee for Standardization, Brussels, 2005.

[5] E. Moliner, M. Martínez-Rodrigo, P. Museros, Dynamic performance of existing double track railway bridges at resonance with the increase of the operational line speed, Eng Struct 132 (2017) 98 109. doi:https://doi.org/10.1016/j.engstruct.2016.11.031

6] K. Liu, G. D. Roeck, G. Lombaert, The effect of dynamic train-bridge interaction on the bridge response during a train passage, J Sound Vib 325 (1) (2009) 240 - 251. doi:https://doi.org/10.1016/j.jsv.2009.03.021

[7] T. Arvidsson, R. Karoumi, Trainbridge interaction a review and discussion of key model parameters, International Journal of Rail Transportation 2 (3) (2014) 147-186. doi:10.1080/23248378.2014.897790

[8] A. Doménech, P. Museros, M. Martínez-Rodrigo, Influence of the vehicle model on the prediction of the maximum bending response of simply-supported bridges under high-speed railway traffic, Eng Struct 72 (2014) 123 - 139. doi:https://doi.org/10.1016/j.engstruct.2014.04.037.

[9] D. Cantero, R. Karoumi, Numerical evaluation of the mid-span assumption in the calculation of total load effects in railway bridges, Eng Struct 107 (2016) 1 - 8 . doi:https://doi.org/10.1016/j.engstruct.2015.11.005.

$645[10]$ P. Museros, E. Alarcon, Influence of the second bending mode on the response of highspeed bridges at resonance, Journal of Structural Engineering 131 (3) (2005) 405 - 415. doi:10.1061/(ASCE) 0733-9445(2005) 131:3(405).

[11] J. Yau, Y. Yang, Vertical accelerations of simple beams due to successive loads traveling at resonant speeds, J Sound Vib 289 (1) (2006) 210 - 228. doi:https://doi.org/10.1016/j.jsv.2005.02.037

[12] J. Rocha, A. Henriques, R. Calçada, Safety assessment of a short span railway bridge for high-speed traffic using simulation techniques, Eng Struct 40 (2012) 141 - 154. doi:https://doi.org/10.1016/j.engstruct.2012.02.024.

[13] C. Rebelo, L. S. oes da Silva, C. Rigueiro, M. Pircher, Dynamic behaviour of twin single-span ballasted railway viaducts - field measurements and modal identification, Engineering Structures 30 (9) (2008) 2460 - 2469. doi:https://doi.org/10.1016/j.engstruct.2008.01.023

655 [14] M. Ülker-Kaustell, R. Karoumi, C. Pacoste, Simplified analysis of the dynamic soil-structure interaction of a portal frame railway bridge, Eng Struct 32 (11) (2010) $3692 \quad 3698$. doi:https://doi.org/10.1016/j.engstruct.2010.08.013.

[15] P. Mellat, A. Andersson, L. Pettersson, R. Karoumi, Dynamic behaviour of a short span soil-steel composite bridge for high-speed railways - field measurements and fe-analysis, Engineering Structures 69 (2014) 49 - 61. doi:https://doi.org/10.1016/j.engstruct.2014.03.004

[16] H. Xia, N. Zhang, Dynamic analysis of railway bridge under high-speed trains, Comput \& Struct 83 (23) (2005) 1891 - 1901. doi:https://doi.org/10.1016/j.compstruc.2005.02.014 
[17] C. Velarde, J. Goicolea, K. Nguyen, J. Garcia-Palacios, I. Diaz, J. Soria, Dynamic analysis of a skew i-beam railway bridge:experimental and numerical, in: I. M. Diaz, J. M. G. Ruigomez, F. J. C. Canas, J. H. G. Palacios, G. K. Nguyen (Eds.), Proceedings of the DINEST 2018, 2018, pp. 118-122.

[18] P. Galvín, A. Romero, E. Moliner, M. Martínez-Rodrigo, Two fe models to analyse the dynamic response of short span simply-supported oblique high-speed railway bridges: Comparison and experimental validation, Eng Struct 167 (2018) 48 - 64 . doi:https://doi.org/10.1016/j.engstruct.2018.03.052

[19] M.D.Martínez-Rodrigo, J. Lavado, P. Museros, Dynamic performance of existing high-speed railway bridges under resonant conditions retrofitted with fluid viscous dampers, Eng Struct 32 (3) (2010) 808 - 828. doi:https://doi.org/10.1016/j.engstruct.2009.12.008

[20] CEN, EN 1991-2, Eurocode 1: Actions on Structures - Part 2: Traffic loads on bridges, European Committee for Standardization, Brussels, 2002.

[21] E. Hamed, Y. Frostig, Free vibrations of multi-girder and multi-cell box bridges with transverse deformations effects, J Sound Vib $279 \quad$ (3) $\quad$ (2005) 699 - 722 . doi:https://doi.org/10.1016/j.jsv.2003.11.037

[22] D. Huang, T. Wang, M. Shahawy, Impact studies of multigirder concrete bridges, Journal of Structural Engineering 119 (8) (1993) 2387-2402. doi:10.1061/(ASCE) 0733-9445(1993) 119:8(2387)

[23] P. Rattigan, A. Gonzalez, E. OBrien, S. Brady, Transverse variation of dynamic effects on beamand-slab medium span bridges, in: N. Millpress Science Publishers, Rotterdam (Ed.), Proc., 6th European Conf. on Structural Dynamics, 2005, pp. 1643-1648.

[24] L. Deng, C. Cai, Development of dynamic impact factor for performance evaluation of existing multi-girder concrete bridges, Engineering Structures 32 (1) (2010) 21 - 31 doi:https://doi.org/10.1016/j.engstruct.2009.08.013

[25] B. D. Allemang RJ, Correlation coefficient for modal vector analysis, in: Proceedings of international modal analysis I, 1982, pp. 110-116.

[26] E. Reynders, System identification methods for (operational) modal analysis: Review and comparison, Archives of Computational Methods in Engineering 19 (1) (2012) 51-124. doi:10.1007/s11831-012-9069-x

[27] R. Pappa, K. Elliot, Consistent mode indicator for the eigensystem realization algorithm, J Guid Control Dynam 16 (5) (1993) $852-860$.

[28] P. Museros, E. Moliner, M. Martínez-Rodrigo, Free vibrations of simply-supported beam bridges under moving loads: Maximum resonance, cancellation and resonant vertical acceleration, Journal of Sound and Vibration 332 (2) (2013) 326 - 345. doi:https://doi.org/10.1016/j.jsv.2012.08.008

[29] P. Museros, E. Moliner, Comments on "vibration of simply supported beams under a single moving load: A detailed study of cancellation phenomenon" by c.p. sudheesh kumar, c. sujatha, k. shankar [int. j. mech. sci. 99 (2015) 40-47, doi: 10.1016/j.ijmecsci.2015.05.001], International Journal of Mechanical Sciences 128-129 (2017) 709 - 713. doi:https://doi.org/10.1016/j.ijmecsci.2016.07.005

[30] A. Doménech, Influencia del modelo de vehículo en la predicción del comportamiento a flexión de puentes isostáticos de ferrocarril para tráfico de alta velocidad, Universitat Politecnica de Valencia, UPV, 2014.

705 [31] M.Ülker-Kaustell, R. Karoumi, Influence of non-linear stiffness and damping on the train-bridge resonance of a simply supported railway bridge, Engineering Structures 41 (2012) $350-355$. doi:https://doi.org/10.1016/j.engstruct.2012.03.060 